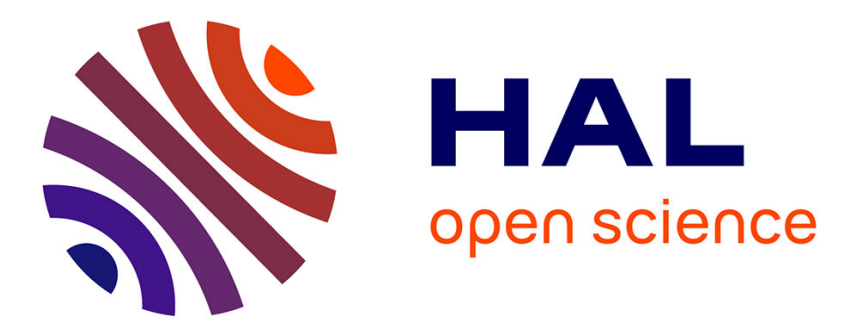

\title{
PROX1 is a specific and dynamic marker of sacral neural crest cells in the chicken intestine
}

Andreia S Margarido, Ludovic Le Guen, Amandine Falco, Sandrine Faure, Norbert Chauvet, Pascal de Santa Barbara

\section{To cite this version:}

Andreia S Margarido, Ludovic Le Guen, Amandine Falco, Sandrine Faure, Norbert Chauvet, et al.. PROX1 is a specific and dynamic marker of sacral neural crest cells in the chicken intestine. Journal of Comparative Neurology, In press, 528, pp.879. 10.1002/cne.24801 . hal-02332399

\section{HAL Id: hal-02332399 \\ https://hal.science/hal-02332399}

Submitted on 24 Oct 2019

HAL is a multi-disciplinary open access archive for the deposit and dissemination of scientific research documents, whether they are published or not. The documents may come from teaching and research institutions in France or abroad, or from public or private research centers.
L'archive ouverte pluridisciplinaire $\mathbf{H A L}$, est destinée au dépôt et à la diffusion de documents scientifiques de niveau recherche, publiés ou non, émanant des établissements d'enseignement et de recherche français ou étrangers, des laboratoires publics ou privés. 


\title{
PROX1 is a specific and dynamic marker of sacral neural crest cells in the chicken intestine
}

RUNNING TITLE: PROX1 expression in sacral NCCs

\author{
Authors \\ Andreia S. Margarido ${ }^{1, *}$, Ludovic Le Guen ${ }^{1, *}$, Amandine Falco ${ }^{1}$, Sandrine Faure ${ }^{1}$, Norbert \\ Chauvet $^{1}$, Pascal de Santa Barbara ${ }^{1}$
}

\section{Affiliations:}

PHYMEDEXP, Université de Montpellier, INSERM, CNRS, Montpellier, France

${ }^{1}$ PhyMedExp, Université de Montpellier, INSERM, CNRS, 34295 Montpellier, France.

*ASM and LLG contributed equally to this work.

\section{Correspondence}

Pascal de Santa Barbara, Université de Montpellier, INSERM, CNRS, Montpellier, France.

Email: Pascal.de-Santa-Barbara@inserm.fr 


\section{Funding information}

LLG was supported by an ARC post-doctoral fellowship. ASM was supported by an Eramus fellowship (University of Lisbon - University of Montpellier). Research was supported by a Trampolin grant from the Association Française contre les Myopathies (AFM) to SF $\left(\mathrm{N}^{\circ} 15681\right)$, grants from AFM $\left(\mathrm{N}^{\circ} 18766 \& \mathrm{~N}^{\circ} 20749\right)$ and the French Patients' Association POIC to PdSB.

\section{ORCID}

Pascal de Santa Barbara https://orcid.org/0000-0001-9040-2481

Sandrine Faure https://orcid.org/0000-0002-8902-8274

Norbert Chauvet https://orcid.org/0000-0003-4388-6422 


\begin{abstract}
The Enteric Nervous System (ENS) is a complex network constituted of neurons and glial cells that ensures the intrinsic innervation of the gastrointestinal tract. ENS cells originate from vagal and sacral neural crest cells that are initially located at the border of the neural tube. In birds, sacral neural crest cells (sNCCs) first give rise to an extramural ganglionated structure (the so-called Nerve of Remak (NoR)) and to the pelvic plexus. Later, sNCCs enter the colon mesenchyme to colonize and contribute to the intrinsic innervation of the caudal part of the gut. However, no specific sNCC marker has been described. Here, we report the expression pattern of Prospero-related homeobox 1 (PROX1) in the developing chick colon. PROX1 is a homeobox domain transcription factor that plays a role in cell type specification in various tissues. Using in situ hybridization and immunofluorescence techniques, we showed that PROX1 is expressed in sNCCs localized in the NoR and in the pelvic plexus. Then, using real-time quantitative PCR we found that PROX1 displays a strong and highly dynamic expression pattern during NoR development. Moreover, we demonstrated using in vivo cell tracing, that sNCCs are the source of the PROX1-positive cells within the NoR. Our results indicate that PROX1 is the first marker that specifically identifies sNCCs. This might help to better identify the role of the different neural crest cell populations in distal gut innervation, and consequently to improve the diagnosis of diseases linked to incomplete ENS formation, such as Hirschsprung's disease.
\end{abstract}

\title{
KEYWORDS
}

Enteric nervous system, sacral neural crest cell, nerve of Remak, colon, Prospero-related homeobox 1, chick embryo, pelvic plexus, RRID: AB_10063408, RRID: AB_63793, RRID: AB_221448, RRID: AB_10013821, $\quad$ RRID:AB_221568, RRID:AB_2762834, RRID:AB_141607, RRID:AB_2536183 


\section{1 - INTRODUCTION}

The gastrointestinal (GI) tract is a complex organ and its functioning relies on the coordinated work of many different tissue types. Indeed, GI smooth muscle, which is innervated by the enteric nervous system (ENS), allows the movement of the ingested food, while the intestinal epithelium and vascular system play a key role in nutrient absorption (Le Guen et al., 2015). Throughout development, the establishment and differentiation of all GI components are precisely regulated. The ENS, which is a complex network of neurons and glial cells, derives from Neural Crest Cells (NCCs) that colonize the immature GI tract from adjacent tissues (Furness, 2005; Uesaka et al., 2016). Specifically, during development, NCCs located at the boundary of the neural plate and non-neural ectoderm undergo epithelial-mesenchymal transition, delaminate from the ectoderm, and migrate through specific pathways to reach their targets where they finally differentiate (Le Douarin and Kalcheim, 1999). Bird models have been used for decades to study NCC migratory routes (for review, Heanue et al., 2016). Experiments with chick-quail chimaeras have identified two NCC types that form the ENS of the GI tract: vagal NCCs (vNCCs) and sacral NCCs (sNCCs). vNCCs migrate ventrally from the neural tube at the level of somites 1-7 on embryonic day 3 (E3) (Yntema and Hammond, 1954; Le Douarin and Teillet, 1973; Espinosa-Medina et al., 2017). They first accumulate in caudal branchial arches before entering the foregut mesenchyme. In the GI tract, vNCCs migrate rostro-caudally, reaching the posterior end at E8-E8.5 in chicken embryos (Le Douarin and Teillet, 1973; Burns and Le Douarin, 1998). Interestingly, their migratory behavior within the GI mesenchyme changes along the anterior-posterior axis. In the preumbilical gut, vNCCs are evenly distributed within the mesenchyme, while in the postumbilical gut they accumulate in the mesenchyme outermost layer. Finally, they reach the hindgut where they colonize the inner submucosa layer.

In chicken embryos, sNCCs originate in the neural tube from somite 28 onwards and give 
rise first to the so-called Nerve of Remak (NoR; an extramural ganglionated structure) and the pelvic plexus. Then, they migrate to the colon mesenchyme where they contribute to $20 \%$ of hindgut neurons (Le Douarin and Teillet, 1973; Serbedzija et al., 1991; Catala et al., 1995; Burns and Le Douarin, 1998; Burns et al., 2000; Nagy et al., 2007). The pelvic plexus is found both in avian and mammalian embryos (Nagy et al., 2007; Serbedzija et al., 1991; Kapur, 2010; Wang et al., 2011a). Conversely, the NoR is unique to birds, and runs in the mesentery, dorsal to the gut, from the cloaca to the duodenum (Suzuki et al., 1996). The NoR sends many nerve branches to the gut derivatives (intestine, cloaca, bursa of Fabricius), and also to other visceral organs, such as ovary and oviduct (Liu et al., 2009).

Thus, vNCCs migrate in a rostro-caudal direction to the gut mesenchyme and colonize the entire chick gut by E8.5, whereas sNCCs enter the distal hindgut mesenchyme in a caudorostral direction (Burns and Le Douarin, 1998; Burns and Le Douarin, 2001). It was previously suggested that sNCC migration is dependent on vNCC colonization. However, in the absence of vNCCs after vagal neural tube ablation, sNCC migrate in an apparently normal manner (Burns and Le Douarin, 2001). Conversely, when the sacral neural tube is transplanted to the vagal area, sNCC migrate rostro-caudally along the gut and stop migrating at the level of the caecum before the colon (Burns et al., 2002). As the hindgut is the GI region most frequently affected by developmental disorders linked to NCC failure to colonize the gut, such as aganglionic megacolon in animals and Hirschsprung's disease in humans, the identification of intrinsic molecular differences between $\mathrm{vNCC}$ and $\mathrm{SNCC}$ is of great interest (Kapur, 2001; Burns and Le Douarin, 2001). Key ENS genes are expressed in both NCC types without qualitative differences (Delalande et al., 2008). Only RET expression is 4-fold higher in vNCCs than in sNCCs. Moreover, RET overexpression in sNCCs leads to the earlier migration to the gut of a larger number of cells (Delalande et al., 2008). However, no specific marker for vNCCs or sNCCs has been identified so far. 
Using a microarray approach to identify candidate genes involved in GI development (Le Guen et al., 2009) that already allowed us to characterize regulators of GI mesenchyme development and differentiation (Notarnicola et al., 2012; McKey et al., 2016), we identified Prospero-related homeobox $1(P R O X 1)$, a homeodomain transcription factor with a key role in cell type specification in various organs and tissues (Stergiopoulos et al., 2015). In mouse embryos, Prox 1 plays an essential role in organ formation, especially brain, retina, lens, liver, pancreas, and the endothelial lymphatic system (Oliver et al., 1993; Tomarev et al., 1996; Wigle and Oliver, 1999; Wigle et al., 1999; Sosa-Pineda et al., 2000; Dyer et al., 2003; Wang et al., 2005; Lavado and Oliver, 2007). In the chick neural tube, PROXI is strongly expressed in interneuron progenitors during development (Misra et al., 2008; Kaltezioti et al., 2010). Moreover, PROX1 regulates cell cycle exit of neural progenitor cells and binary fate decision (Kaltezioti et al., 2014). In the present study, we investigated PROX1 temporal and spatial expression in the developing chick colon. We found that PROX1 expression is strong and highly dynamic during the development of the NoR and the pelvic plexus. We also showed by in vivo cell tracing that sNCCs initially located in the neural tube from somite 28 onwards are at the origin of the PROX1-positive cells present in the NoR.

\section{2 - MATERIALS AND METHODS}

\section{1 - Animals}

Timed fertilized white Leghorn eggs (Haas Farm, France) were kept at $38^{\circ} \mathrm{C}$ in a humidified incubator (Coudelou, France) until use. Embryos were staged according to Hamburger and Hamilton (HH) (Hamburger and Hamilton, 1951). GI tissues were dissected from chick embryos and staged according to the embryonic day (E) (Southwell, 2006). Dissected GI tissues were fixed in $4 \%$ paraformaldehyde at room temperature for $1 \mathrm{~h}$, washed in PBS, 
gradually dehydrated in methanol and stored at $-20^{\circ} \mathrm{C}$ before processing for whole-mount in situ hybridization, as described below.

\section{2 - Whole-mount in situ hybridization}

Whole-mount in situ hybridization was carried out as previously described using antisense SOX10 (Moniot et al., 2004; Bourret et al., 2017) and PROX1 riboprobes. For this, E6 GI tract total RNA and primers specific for chick PROXI (Gene Bank ID: NM_001005616.1; forward: 5' -TGT AAA GTT CAA CAG ATG CAT TAC C- 3', reverse: 5' -ATG TTA AGG GTC TCG GGC AA- 3') were used to amplify chick PROX1 cDNA. The resulting 616 base pair (bp) fragment was cloned in the pGEM-T Easy vector (Invitrogen) and sequenced to verify the identity.

GI tissues were gradually rehydrated in PBS, washed in PBS $/ 0.1 \%$ Tween (PBT) and incubated in $6 \%$ hydrogen peroxide for $1 \mathrm{~h}$ (Sigma, France). Samples were then permeabilized by treatment with proteinase $\mathrm{K}(10 \mu \mathrm{g} / \mathrm{ml})$ for $10 \mathrm{~min}$, washed with glycine in PBT, and fixed in $4 \%$ paraformaldehyde $/ 0.2 \%$ glutaraldehyde in PBT for $20 \mathrm{~min}$. Then, samples were hybridized with digoxigenin-labeled (Roche) antisense $S O X 10$ or $P R O X 1$ riboprobes at $70^{\circ} \mathrm{C}$ overnight. After washes at $70^{\circ} \mathrm{C}$, samples were incubated in $10 \%$ sheep serum at room temperature for $2.5 \mathrm{~h}$, and finally mixed with a pre-adsorbed anti-digoxigenin antibody coupled with alkaline phosphatase (Roche) at $4^{\circ} \mathrm{C}$ overnight. Complexes were detected with BM Purple, a chromogenic substrate for alkaline phosphatase (Roche).

\section{3 - Quantitative real-time RT-PCR}

Total RNA was extracted from E5 to E12 chick colons with the HighPure RNA Isolation Kit (Roche). Reverse transcription (RT) was performed with the Verso cDNA Synthesis Kit (Thermo Scientific) and quantitative real time PCR was performed using the LightCycler 
technology (Roche Diagnostics). PCR primers (Supplementary Table 1) were designed using the LightCycler Probe Design software-2.0. For each developmental stage, each analyzed sample corresponded to total RNA pooled from three individual colons. Three samples were used at each stage to evaluate the expression of PROX1, SOX10 and SM22. Expression levels were determined with the LightCycler analysis software (version 3.5) relative to standard curves. Data were presented as the expression levels of PROX1, SOX10 and SM22 relative to the expression of the reference gene GAPDH. The relative mRNA expression was calculated using the $2^{-\triangle \Delta C T}$ method (Faure et al., 2015; McKey et al., 2016). Among the eight reference genes tested, GAPDH was selected based on its expression stability using the geNorm software. According to this program, GAPDH M value was 0.24 , well below the accepted cutoff for expression stability (i.e., 0.5) (Vandesompele et al. 2002).

\section{4 - Antibodies}

The anti-TUJ1 antibody (Covance, Princeton, NJ, USA; mouse monoclonal, cat. \#MMS-435P, RRID: AB_10063408) was raised against microtubules derived from rat brain and recognizes an epitope located within the last $15 \mathrm{C}$-terminal residues of neuron-specific class III $\beta$ tubulin (Lee MK et al., 1990). It cross-reacts with avian class III $\beta$ tubulin, but not with tubulin in glial cells. The anti-HNK-1 antibody (LabVision/Neo-Markers, CA, USA; mouse monoclonal, cat. \#MS-1163-P1, RRID: AB_63793) recognizes a N-linked carbohydrate (Abo and Balch, 1981) and is a well-known avian neural crest marker (BronnerFraser, 1986; Moniot et al., 2004; Nagy et al., 2007; Faure et al., 2015; Bourret et al., 2017). The anti-HUC/D antibody (Invitrogen; mouse monoclonal, clone 16A11, cat. \#A-21271, RRID: AB_221448) specifically recognizes neuronal perikarya (Marusich et al., 1994; Notarnicola et al., 2012). The anti-PROX1 antibody (RELIA Tech, Germany; rabbit 
polyclonal, cat. \#102-PA32, RRID: AB_10013821) used in this study was generated against the highly conserved C-terminus of recombinant human PROX1 produced in E. coli (amino acid 546 to $737,100 \%$ identical to avian PROX1). In western blot experiments with E15 chick pancreas-duodenum samples, the anti-PROX1 antibody identified a single band of around $83 \mathrm{kDa}$ that corresponds to the predicted size of chick PROX1 (Supplementary Figure 1a). Moreover, this antibody detected PROX1-positive cells in chick E15 pancreatic epithelium (Supplementary Figure 1b), consistent with a previous report (Westmoreland et al., 2012). Finally, PROX1 immunostaining was comparable to the results obtained by in situ hybridization with the antisense $P R O X 1$ probe.

\section{5 - Immunofluorescence experiments}

Chick gut samples were fixed in $4 \%$ paraformaldehyde, followed by gradual incubation in sucrose solution. Then, samples were embedded in OCT and stored at $-80^{\circ} \mathrm{C}$ before cutting 10 $\mu \mathrm{m}$ cryosections collected on poly-d-lysine-coated slides (Thermo Fisher). Immunofluorescence experiments were performed using antibodies against PROX1 (Reliatech; rabbit, dilution 1/400), TUJ1 (Covance; mouse, dilution 1/500), GFP (ThermoFisher; clone 3E6, mouse, cat. A-11120, RRID: RRID:AB_221568, dilution 1/400) and HNK-1 (NeoMarkers; mouse, dilution 1/200). Nuclei were labeled with Hoechst 33342 (Invitrogen, France). After washing, slides were incubated with Alexa 488 anti-mouse (Thermo Fischer Scientific; cat. \#A-21202, RRID:AB_141607, 1:2000 dilution) and Alexa 555 anti-rabbit (Thermo Fischer Scientific; cat. \#A32794, RRID:AB_2762834, 1:2000 dilution) or Alexa 647 anti-rabbit (Thermo Fischer Scientific; cat. A-31573, RRID:AB_2536183, 1:2000 dilution) for 30min. Sections were rinsed and mounted with Fluorescent Mounting Medium (Dako, France). Immunofluorescence control experiments were performed without primary antibodies (data not shown). Cells were imaged with a Zeiss 
AxioVision fluorescence microscope using standard filters, or a ZEISS LSM800 confocal laser scanning microscope. PROX1-positive cells in the developing NoR were quantified with the Fiji image analysis software. Image background was removed using on a "rolling ball" algorithm, and a median filter was applied followed by thresholding. Images were converted to a binary format and the areas of interest were selected and measured (TUJ1-positive area; $\mu \mathrm{m} 2)$. PROX1 cells were then counted in such areas using the "analyze particle" plugin. The percentage of PROX1-positive cells per TUJ1-positive area $(\mu \mathrm{m} 2)$ was calculated using the Prism7 software.

\section{6 - In ovo electroporation to target sNCCs}

Chick eggs were incubated for about 2.5 days until HH16 when integrative plasmids (pCAGGS-T2TP and pT2K-CAGGS-EGFP) (Wang et al., 2011b) were injected in the caudal neural tube (somite 25) using a micro-injector and the site was identified with Phenol Red Solution (Sigma, ref.: P0290). After microinjection, gold plated electrodes (Electroporation System ECM 830, BTX) were placed on both sides of the caudal neural tube and electroporation was performed bilaterally at 25V (3 pulses of 5ms) (Fort et al., 2011). Then, eggs were sealed and incubated up to E6.5. After colon dissection, GFP signal was directly evaluated before immunofluorescence analysis.

\section{3 - RESULTS}

\section{1 - PROX1 expression in the chick embryonic gastrointestinal tract}

Among the genes with high expression level in the developing chick colon compared with the developing stomach identified by RNA microarray assays (Supplementary Table 2), PROXI was strongly expressed in E5 and E6 chick colon, and then its expression level decreased in 
E9 colon. Conversely, it was faintly expressed in E6 and E9 stomach (Figure 1a). This pattern is unique compared with the expression of key NCC genes (SOX10 and RET) and markers of differentiated smooth muscle (SM22 and CNN1) (Figure 1a). Analysis of its expression pattern in the whole gastrointestinal tract at E6 by whole-mount in situ hybridization showed that PROXI was expressed in the dorsal part of the colon and in pancreas (Figure 1b). As the NoR is situated in the dorsal part of the colon, the expression of SOX10, a marker of migrating NCCs, was also investigated by whole-mount in situ hybridization. At E6, SOX10 signal revealed the presence of vNCCs in the gizzard, their advancing front at the level of the small intestine, and the presence of sNCCs in the NoR (Figure 1b), where PROXI was also expressed. Analysis of PROX1 expression in the developing chick colon using an antibody that recognizes also the Gallus gallus PROX1 protein (Supplementary Figure 1) showed that PROX1 was expressed in the NoR (Figure 1c). Moreover, in E6 colon sections, PROX1 colocalized with TUJ1-positive cells that define the NoR (Figure 1d) and also with HUC/Dpositive cells (a marker of neurons present in the NoR) (Figure 1e). Altogether, our data indicate that PROX1 is expressed by neurons of the NoR that are considered to originate from sNCCs (Le Douarin and Teillet, 1973; Serbedzija et al., 1991; Catala et al., 1995).

\section{2 - PROX1 expression in the developing chick colon}

As PROX1 was specifically expressed in the NoR, its temporal expression profile was thoroughly characterized and compared with that of SOXIO (NCC marker) in developing colon samples from E5 to E9 by whole-mount in situ hybridization (Figures 2a, 2b). At E5 and E6, SOX10 expression in the colon was restricted to the NoR, thus identifying the sNCC population (Figure 2b). As vNCCs colonize the GI tract along an anterior-posterior migration axis, at E7 SOX10 expression in the small intestine, ceca and colon identified vNCCs. These

cells then reached the most caudal part of the colon at E9 (Figure 2b). At E8, SOX10 
expression highlighted the pelvic plexus surrounding the cloaca and connected to the NoR (Figure $2 \mathrm{~b}$ and Supplementary Figure $2 \mathrm{~b}$, arrows). PROXI was strongly expressed in the NoR from E5 (Figure 2a) and particularly at E6. In contrast to SOX10, PROX1 expression in the NoR quickly decreased from E7 onwards. At E8 PROX1 was faintly detected in the NoR, while its expression remained high in the pelvic plexus (Figure 2a and Supplementary Figure 2a, arrows). Moreover, PROXI defined fibers that are present in the caudal part of the E8 colon and are connected to the NoR (Supplementary Figure 2a, arrowheads). At E9, PROX1 could be detected in the pelvic plexus (Figure 2a, arrow), but not in the NoR.

Quantification of PROX1, SOX10 (NCC marker) and SM22 (smooth muscle marker) expression levels by real-time quantitative RT-PCR (Figures 2c-e) using specific Gallus gallus primers (Supplementary Table 1) showed that SOX10 and SM22 transcript levels progressively increased during colon development from E5 to E12 (Figures 2d, 2e). PROX1 was already strongly expressed at E5. Then, its expression increased at E6 and E7, and started to decrease from E8 (Figure 2c).

Immunofluorescence analysis of PROX1 and TUJ1 (NCC marker in the NoR) protein expression in E6 to E9.5 colon transverse sections (Figure 3, Supplemental Figure 3) showed that at E8, TUJ1-positive cells were in the inner layer of the colon mesenchyme. This stage corresponds to the time of colonization by vNCCs (Figure 3, Supplemental Figure 3). In addition, TUJ1-positive cells were detected also in the outer layer of the colon mesenchyme starting from E7.5, which corresponds to the presence of sNCC in the colon (Figure 3, Supplemental Figure 3). During this period, PROX1-positive cells were observed in the NoR, and at E9.5 they could not be detected in the colon mesenchyme and in sNCCs that have already migrated to the mesenchyme (Figure 3; Supplementary Figure 3). Although PROX1 expression was mainly restricted to the NoR, some PROX1-positive cells were located dorsally to the NoR and corresponded to developing lymphatic cells (white arrows, Figure 3). 
Quantification of PROX1-positive sNCCs in the NoR revealed a strong decrease in their number from E6 $\left(10.7 \times 10^{-3}\right.$ cells per $\left.\mu \mathrm{m}^{2}\right)$ to E9 $\left(0.86 \times 10^{-3}\right.$ cells per $\left.\mu \mathrm{m}^{2}\right)$ (Figure 4$)$. These findings show that PROX1 is dynamically expressed in the developing chick colon and accurately defines the population of sNCCs that reside in the NoR and in the pelvic plexus from E6 to E9.

\section{3 - Origin of the PROX1-positive cells detected in the nerve of Remak}

As sNCCs originate from NCCs present in the neural tube adjacent to somite 28 caudalwards, PROXI spatiotemporal expression pattern was examined also during early development from HH11 (E2) to HH24 (E4.5). Whole-mount in situ hybridization showed that PROXI was expressed in the developing eye, cranial neural tube, heart, liver, and optic and otic placodes. At HH24, PROX1 was observed in somites and mid-neural tube (Figure 5a). However, at these stages, PROX1 expression could not be detected in the caudal neural tube where sNCCs originate (Figure 5a). Then, analysis of the expression of PROX1 and HNK-1 (a marker of migrating NCCs) by immunofluorescence in caudal colon transversal sections from HH18 to HH23 embryos (Figures 5b-d) showed that at HH18 and HH19, HNK1-positive sNCCs delaminated from the neural tube and migrated to the embryo body to reach the dorsal part of the colon and form the future NoR (Figures 5b, 5c). At HH18 and HH19, PROX1 was expressed in cells localized in the neural tube and in isolated cells that will constitute the lymphatic vessels (Figures 5b, 5c), but not in sNCCs (Figures 5b, 5c). Conversely, at HH23, PROX1 was expressed in HNK-1-positive cells that constitute the developing NoR (Figures 5d, 5e).

As PROX1 was not expressed in migrating sNCCs that have not reached the NoR yet, sNCCs located at the level of somite 28 and caudal-wards were labeled by bilateral electroporation of integrative GFP plasmids in the neural tube at HH16 before delamination 
(Figure 6a). At E6.5, most GFP-expressing cells were in the most dorsal part of the colon (Figure 6b). Immunofluorescence analysis of GFP and PROX1 expression in E6.5 colon samples after electroporation showed that GFP-positive cells in the NoR expressed also PROX1 (Figure 6c). Moreover, confocal microscopy analysis indicated that GFP-positive cells in the NoR expressed both PROX1 and HUC/D (Figure 6d), demonstrating that the PROX1-positive cells in the developing NoR are sNCCs from the caudal neural tube.

\section{4 - DISCUSSION}

The ENS derives from NCCs that originate from multiple positions to form a complex network of neurons and glial cells. Among them, sNCCs contribute to the intrinsic innervation of the posterior gut in vertebrates (Le Douarin and Teillet, 1973; Serbedzija et al., 1991; Catala et al., 1995; Burns and Le Douarin, 1998; Burns et al., 2000; Nagy et al., 2007; Serbedzija et al., 1991; Kapur, 2000; Wang et al., 2011a). A failure in NCC colonization of the gut leads to an incomplete formation of ENS (agangliogenesis) in the distal gut, a congenital obstructive disorder named the Hirschsprung's disease (de Santa Barbara et al., 2002; Amiel et al., 2008; Etchevers et al., 2019). Unfortunately, the mechanisms leading to this pathology are not fully understood. A better knowledge about NCC development and the contribution of the different NCC populations to the distal gut innervation might improve their diagnosis. Although the origin and pathways of sNCC delamination and colonization are well described in avian and mouse models (Haenue et al., 2016; Kapur, 2000; Wang et al., 2011a), no specific sNCC marker has been described so far (Haenue et al., 2016; Memic et al., 2018).

Using microarray, in situ hybridization and immunofluorescence approaches, we found that PROX1 is expressed in the NoR located dorsally to the colon and small intestine from E5 to E8. PROX1 is downregulated when sNCCs migrate to the colon/small intestine around 
E7.5-E8. As in situ hybridization and immunofluorescence approaches are not quantitative techniques, we quantified by RT-PCR the relative abundance of PROXI transcripts during colon development. We confirmed PROXI dynamic expression and its downregulation at E8E9, when sNCCs migrate to the colon mesenchyme. Interestingly, at these stages, no expression of PROX1 was detected in SOX10-positive vNCCs that were migrating anteriorposteriorly. The integrative expression of GFP in sNCCs before their migration to the NoR confirmed that PROX1-expressing cells found in the NoR at E6 derive from sNCCs. In vertebrates (birds, humans and mice), sNCCs form the pelvic plexus that contribute to the hindgut ENS (Serbedzija et al., 1991; Kapur, 2000; Nagy et al., 2007; Wang et al., 2011a). PROX1 is also expressed in the pelvic plexus at E8 and E9. In vertebrate, PROX1 is implicated in cell type specification in various organs and tissues (Stergiopoulos et al., 2015), but its role in ENS organization has not been addressed yet. In heterozygous mice in which Proxl was inactivated by in-frame insertion of the lac $Z$ gene, lacZ expression was observed in the dorsal part of the caudal hindgut (Burke and Oliver, 2002), where the pelvic plexus is located (Wang et al., 2011a). Moreover, high resolution in situ hybridization in mouse embryo sections demonstrated Proxl expression in the dorsal part of the caudal hindgut at E14.4 (https://gp3.mpg.de/GP-IMG/JPG/EG/EG00000615/EG00000615_00013B.jpg). Altogether, PROX1 expression in the NoR and also in the pelvic plexus suggests that PROX1 could be a specific marker of sNCCS.

PROX1 is a member of the homeobox transcription factor family and through its homeobox domain can regulate positively or negatively the transcription of target genes (Stergiopoulos et al., 2015). For instance, Kaltezioti and colleagues showed that PROX1 represses NOTCH1 signaling in the chick and mouse neural tube (Kaltezioti et al., 2010). As NOTCH1 signaling inhibits neurogenesis, PROX1 repression of NOTCH1 activity leads to neural progenitor cell differentiation. NOTCH1 and SOX10 maintain the ENS progenitor pool 
and later promote neurogenesis and/or gliogenesis through additional regulatory mechanisms at different developmental stages. Our results show that SOX10 is expressed in the NoR, in migrating sNCCs and in vNCCs from E5 to E9. Conversely, PROX1 is only expressed in the NoR between E5 and E8 before sNCC migration to the colon/small intestine. PROX1 could have a role in the mechanisms that regulate the dual function of SOX10 and NOTCH1. It could be hypothesized that in the NoR, SOX10 and NOTCH1 maintain the sNCC pool of progenitors before PROX1 expression. Upon PROX1 expression, NOTCH1 starts to be downregulated and this induces neuronal differentiation. Then, PROX1 downregulation might lead to upregulation of NOTCH1 that together with SOX10 can now induce gliogenesis. However, although NOTCH1 can also contribute to NCC migration when PROX1 is still expressed in the NoR, some sNCCs are already migrating to the colon. Another pathway involved in ENS development is the HEDGEHOG signaling cascade that has a role in NCC migration and could inhibit the NOTCH pathway (Liu and Ngan, 2014; Nagy et al., 2016). New studies are now needed to identify PROX1 downstream targets, which will also lead to the discovery of more sNCC-specific markers, providing new tools for the characterization of colon ENS-associated pathologies. Altogether, our results have identified a novel NCC marker that allows the distinction between vNCCs and sNCCs.

\section{ACKNOWLEDGMENTS}

The authors thank all members of the INSERM Team "Development of visceral smooth muscle and Associated Pathologies" for technical help and comments. The authors thanks Alan Burns (UCL, London, UK) for fruitful discussion and advises.

\section{DATA AVAILABILITY STATEMENT}

All plasmids developed during this study are available upon request. 


\section{CONFLICT OF INTEREST}

The authors have nothing to disclose and no conflict of interest.

\section{AUTHOR CONTRIBUTIONS}

ASM and LLG performed in situ hybridization, immunofluorescence and quantitative RTPCR experiments. LLG and PdSB performed electroporation experiments. AF analyzed the immunofluorescence data. SF and NC performed the microarray screen and analysis. All authors contributed to the writing and critical revision of the manuscript. 


\section{FIGURE LEGENDS}

FIGURE 1 Spatial and temporal expression of PROX1 mRNA during embryonic development of the chick GI tract. Heatmap for PROX1, SM22, CNN1, SOX10 and RET expression in chick colon (from E5, E6, and E9) and gizzard (E6 and E9) samples (a). Highest signals are in red, and lowest signals are in green. PROXI mRNA is dynamically expressed in colon compared to gizzard. SM22 and CNN1 are two markers of differentiated smooth muscle. Whole-mount in situ hybridization analysis of PROX1 and SOX10 (b) in the E6 chick GI tract. $P R O X 1$ is expressed in pancreas, and the dorsal part of the colon. SOX10 staining showed the presence of vagal NCCs in the gizzard and mid-small intestine. SOX10 also is expressed in the NoR localized in the dorsal part of the colon. Unspecific PROXI probe trapping is observed in the lumen of the gizzard. Scale bar: $1 \mathrm{~mm}$. Abbreviations: col.: colon; giz: gizzard; lg: lung; NoR: Nerve of Remak; panc: pancreas; s.i.: small intestine. Immunohistochemistry analysis of PROX1 expression in E7 chick colon cryostat sections (representative image) (c). PROX1-positive cells are mainly observed in the NoR. Scale Bar: $100 \mu \mathrm{m}$. (d) Immunofluorescence analysis using anti-PROX1 and -TUJ1 antibodies in E6 chick colon sections (upper part of the colon). PROX1 (nuclear expression) and TUJ1 (cytoplasmic expression) are co-localized in the NoR. Scale Bars: $25 \mu \mathrm{m}$. (e) Confocal immunofluorescence analysis of PROX1 and HUC/D expression in E6 chick colon sections (lower part of the colon). Nuclear PROX1 and HUC/D are co-expressed in neurons of the NoR. Scale Bars: $25 \mu \mathrm{m}$. Abbreviations: Epith.: epithelium; NoR: Nerve of Remak.

FIGURE 2 Spatial and temporal expression of $P R O X 1$ mRNA in the chick developing colon. Whole-mount in situ hybridization analysis of PROX1 (a) and SOX10 (b) in E5 to E9 chick colon samples. Scale Bars: $1 \mathrm{~mm}$. PROXI expression is detected in the NoR from E5 to E8, 
but not at E9. In addition, PROXI expression is observed in the pelvic plexus (PP) at E8 and E9. SOX10 expression is restricted to the NoR at E5 and E6. Moreover, SOX10 is also observed in migrating vNCCs located in the small intestine and ceca at E7 and in the colon and pelvic plexus (PP) at E8 (arrowheads). At E9, the whole colon is completely colonized by NCCs and SOX10 is exclusively expressed by the glial lineage. Relative mRNA expression levels of PROX1 (c), SOX10, (d) and SM22 (e) in pooled E5 to E12 colon samples determined by quantitative RT-PCR. Data shown are the mean \pm SD expression levels relative to $G A P D H$. Each measurement was done using total RNA pooled from three individual colons (three pools for each stage). PROX1 mRNA levels is highest at E6. SOX10 and SM22 expression levels progressively increase during colon development.

FIGURE 3 Spatial and temporal expression of PROX1 protein in the chick developing colon. Immunofluorescence analysis of PROX1 and TUJ1 expression in transverse cryosections from E6 to E9 chick colons. TUJ1 is detected in sNCCs located in the NoR from E6 to E9. At E8, numerous TUJ1-positive sNCCs migrated to the outer part of the colon mesenchyme. In addition, at E8 TUJ1-positive vNCCs are present in the inner part of the colon mesenchyme. Two enteric plexuses are present at E9: the myenteric (MP) and submucosa (SP) plexus. At E6, PROX1 is observed in the majority of cells present in the NoR. Then, PROX1 expression in these cells decreased from E7 to E8, and remained only in some isolated cells at E9. PROX1 is also expressed in lymphatic endothelial cells (white arrows) located close to the NoR. Scale Bars: $100 \mu \mathrm{m}$.

FIGURE 4 Quantification of the number of PROX1-positive cells in the NoR at E6 to E9 (data from Figure 3). The number of cells in which PROX1 is detected in the nucleus was determined relative to the TUJ1-positive cell area in the NoR $(n=2-4$ colon/small intestine 
sections/stage). The number of PROX1-positive cells progressively decreased over time: $10.7 \times 10^{-3}$ cells $/ \mu \mathrm{m}^{2}$ at $\mathrm{E} 6,6.19 \times 10^{-3}$ cells $/ \mu \mathrm{m}^{2}$ at $\mathrm{E} 7,3.89 \times 10^{-3}$ cells $/ \mu \mathrm{m}^{2}$ at $\mathrm{E} 8$, and $0.86 \times 10^{-3}$ cells $/ \mu \mathrm{m}^{2}$ at E9. Data are the mean $\pm \mathrm{SD}$.

FIGURE 5 PROX1 expression in early developing chick colon. PROX1 mRNA expression was analyzed by whole-mount in situ hybridization in Hamburger and Hamilton Stage 11 (HH11) to HH23 embryos (a). PROX1 is expressed in the developing eye, cranial neural tube (cNT), heart, liver, optic (op. pl.) and otic (ot. pl.) placodes. At HH24, PROX1 expression is observed in somites and mid-neural tube. Scale Bars: $1 \mathrm{~mm}$. Immunofluorescence analysis of PROX1 and HNK-1 expression in transverse cryosections of HH18 to HH23 chick embryos at the posterior splanchnic mesoderm (spl. m.) and gut levels (b, c, d). At HH18 and HH19, HNK-1-positive sNCCs delaminate from the neural tube (NT) to reach the colon (Col.) and to form first the NoR at HH23. PROX1- and HNK-1-positive cells are only observed at HH23 when the NoR is formed. Scale Bars: $50 \mu \mathrm{m}$. Immunofluorescence analysis of PROX1 and HNK-1 expression in sagittal cryosections of HH23 chick embryos (e). Co-expression of PROX1 and HNK-1 is observed along the dorsal part of the colon (Col.) in the developing NoR. Scale Bars: $100 \mu \mathrm{m}$.

FIGURE 6 Origin of PROX1-expressing cells present in the NoR. Electroporation procedure to target sNCCs before their delamination from the neural tube (a). Integrative GFPexpressing plasmids were injected in the caudal neural tube at HH16 with Phenol Red Solution. After electroporation, eggs were put back in the incubator. Representative image to show the electroporation efficiency in targeting the neural tube (NT) at $24 \mathrm{~h}$ post-injection, before sNCC migration (a). Representative image of an E6.5 chick colon after integrative GFP plasmid electroporation at HH16 observed with white light and with a fluorescence 
stereomicroscope (b). Electroporated sNCCs are observed in the E6.5 NoR located dorsally to the colon (Col.). Immunofluorescence analysis of PROX1 and GFP expression in E6.5 colon transverse cryosections after electroporation at HH16 to visualize the NoR (c). Confocal immunofluorescence analysis of PROX1, HUC/D and GFP expression in E6.5 colon transverse cryosections after electroporation at HH16 to visualize the NoR (d). Cells that coexpress GFP, PROX1 and HUC/D are observed in the NoR. Epith: epithelium. 


\section{REFERENCES}

Abo T, Balch CM. 1981. A differentiation antigen of human NK and K cells identified by a monoclonal antibody (HNK-1). J Immunol 127:1024-1029.

Amiel J, Sproat-Emison E, Garcia-Barcelo M, Lantieri F, Burzynski G, Borrego S, Pelet A, Arnold S, Miao X, Griseri P, Brooks AS, Antinolo G, de Pontual L, Clement-Ziza M, Munnich A, Kashuk C, West K, Wong KK, Lyonnet S, Chakravarti A, Tam PK, Ceccherini I, Hofstra RM, Fernandez R; Hirschsprung Disease Consortium. 2008. Hirschsprung disease, associated syndromes and genetics: a review. $J$ Med Genet 45:114.

Bourret A, Chauvet N, de Santa Barbara P, Faure S. 2017. Colonic mesenchyme differentiates into smooth muscle before its colonization by vagal enteric neural crest-derived cells in the chick embryo. Cell Tissue Res 368:503-511.

Bronner-Fraser M. 1986. Analysis of the early stages of trunk neural crest migration in avian embryos using monoclonal antibody HNK-1. Dev Biol 115:44-55.

Burke Z, Oliver G. 2002. Prox1 is an early specific marker for the developing liver and pancreas in the mammalian foregut endoderm. Mech Dev 118:147-155.

Burns AJ, Le Douarin NM. 1998. The sacral neural crest contributes neurons and glia to the post-umbilical gut: spatiotemporal analysis of the development of the enteric nervous system. Development 125:4335-4347.

Burns AJ, Champeval D, Le Douarin NM. 2000. Sacral neural crest cells colonise aganglionic hindgut in vivo but fail to compensate for lack of enteric ganglia. Dev Biol 219:30-43.

Burns AJ, Le Douarin NM. 2001. Enteric nervous system development: analysis of the selective developmental potentialities of vagal and sacral neural crest cells using quailchick chimeras. Anat Rec 262:16-28. 
Burns AJ, Delalande JM, Le Douarin NM. 2002. In ovo transplantation of enteric nervous system precursors from vagal to sacral neural crest results in extensive hindgut colonisation. Development 129:2785-2796.

Catala M, Teillet MA, Le Douarin NM. 1995. Organization and development of the tail bud analyzed with the quail-chick chimaera system. Mech Dev 51:51-65.

de Santa Barbara P, van den Brink GR, Roberts DJ. 2012. Molecular etiology of gut malformations and diseases. Am J Med Genet 115:221-230.

Delalande JM, Barlow AJ, Thomas AJ, Wallace AS, Thapar N, Erickson CA, Burns AJ. 2008. The receptor tyrosine kinase RET regulates hindgut colonization by sacral neural crest cells. Dev Biol 313:279-292.

Dyer MA, Livesey FJ, Cepko CL, Oliver G. 2003. Prox1 function controls progenitor cell proliferation and horizontal cell genesis in the mammalian retina. Nat Genet 34:53-58.

Espinosa-Medina I, Jevans B, Boismoreau F, Chettouh Z, Enomoto H, Müller T, Birchmeier C, Burns AJ, Brunet J-F. 2017. Dual origin of enteric neurons in vagal Schwann cell precursors and the sympathetic neural crest. Proc Natl Acad Sci USA 114:11980-11985.

Etchevers HC, Dupin E, Le Douarin NM. 2019. The diverse neural crest: from embryology to human pathology. Development 146:pii: dev169821.

Faure S, McKey J, Sagnol S, de Santa Barbara P. 2015. Enteric neural crest cells regulate vertebrate stomach patterning and differentiation. Development 142:331-342.

Fort P, Guémar L, Vignal E, Morin N, Notarnicola C, de Santa Barbara P, Faure S. 2011. Activity of the RhoU/Wrch1 GTPase is critical for cranial neural crest cell migration. Dev Biol 350:451-463.

Furness JB. 2005. The Enteric Nervous System. Blackwell Publishing. Oxford.

Hamburger V, Hamilton HL. 1951. A series of normal stages in the development of the chick embryo. J Morphol 88:49-92. 
Heanue TA, Shepherd IT, Burns AJ. 2016. Enteric nervous system development in avian and zebrafish models. Dev Biol 417:129-138.

Kaltezioti V, Antoniou D, Stergiopoulos A, Rozani I, Rohrer H, Politis PK. 2014. Prox1 regulates Olig2 expression to modulate binary fate decisions in spinal cord neurons. $J$ Neurosci 34:15816-15831.

Kaltezioti V, Kouroupi G, Oikonomaki M, Mantouvalou E, Stergiopoulos A, Charonis A, Rohrer H, Matsas R, Politis PK. 2010. Prox1 regulates the notch1-mediated inhibition of neurogenesis. PLoS Biol 8:e1000565.

Kapur RP. 2000. Colonization of the murine hindgut by sacral crest-derived neural precursors: experimental support for an evolutionarily conserved model. Dev Biol. 227:146-155.

Lavado A, Oliver G. 2007. Prox1 expression patterns in the developing and adult murine brain. Dev Dyn 236:518-524.

Le Douarin NM, Teillet MA. 1973. The migration of neural crest cells to the wall of the digestive tract in avian embryo. J Embryol Exp Morphol 30:31-48.

Le Douarin NM, Kalcheim C, 1999. The Neural Crest (2nd edition). Cambridge University Press. UK.

Le Guen L, Notarnicola C, de Santa Barbara P. 2009. Intermuscular tendons are essential for the development of vertebrate stomach. Development 136:791-801.

Le Guen L, Marchal S, Faure S, de Santa Barbara P. 2015. Mesenchymal-epithelial interactions during digestive tract development and epithelial stem cell regeneration. Cell Mol Life Sci 72:3883-3896.

Lee MK, Rebhun LI, Frankfurter A. 1990. Posttranslational modification of class III betatubulin. Proc Natl Acad Sci U S A. 87:7195-7199. 
Liu J, Qin J, Feng Y, Bao H, Zhou Q, Chen Q. 2009 Distribution of vasoactive intestinal peptide and substance $\mathrm{P}$ messenger ribonucleic acid in intestinal nerve of Remak of chicken. Poult Sci 88:1421-1426.

Liu JA, Ngan ES. 2014. Hedgehog and Notch signaling in enteric nervous system development. Neurosignals. 22:1-13

Marusich MF, Furneaux HM, Henion PD, Weston JA. 1994. Hu neuronal proteins are expressed in proliferating neurogenic cells. J Neurobiol. 25:143-155.

McKey J, Martire D, de Santa Barbara P, Faure S. 2016. LIX1 regulates YAP1 activity and controls the proliferation and differentiation of stomach mesenchymal progenitors. $B M C$ Biol 14:34.

Memic F, Knoflach V, Morarach K, Sadler R, Laranjeira C, Hjerling-Leffler J, Sundström E, Pachnis V, Marklund U. 2018. Transcription and Signaling Regulators in Developing Neuronal Subtypes of Mouse and Human Enteric Nervous System. Gastroenterology. 154:624-636.

Misra K, Mishra K, Gui H, Matise MP. 2008. Prox1 regulates a transitory state for interneuron neurogenesis in the spinal cord. Dev Dyn 237:393-402.

Moniot B, Biau S, Faure S, Nielsen CM, Berta P, Roberts DJ, de Santa Barbara P. 2004. SOX9 specifies the pyloric sphincter epithelium through mesenchymal-epithelial signals. Development 131:3795-3804.

Nagy N, Brewer KC, Mwizerwa O, Goldstein AM. 2007. Pelvic plexus contributes ganglion cells to the hindgut enteric nervous system. Dev Dyn 236:73-83.

Nagy N, Barad C, Graham HK, Hotta R, Cheng LS, Fejszak N, Goldstein AM. 2016. Sonic hedgehog controls enteric nervous system development by patterning the extracellular matrix. Development. 143:264-75. 
Notarnicola C, Rouleau C, Le Guen L, Virsolvy A, Richard S, Faure S, De Santa Barbara P. 2012. The RNA-binding protein RBPMS2 regulates development of gastrointestinal smooth muscle. Gastroenterology 143:687-697.e9.

Oliver G, Sosa-Pineda B, Geisendorf S, Spana EP, Doe CQ, Gruss P. 1993. Prox 1, a prospero-related homeobox gene expressed during mouse development. Mech Dev 44:316.

Serbedzija GN, Burgan S, Fraser SE, Bronner-Fraser M. 1991. Vital dye labelling demonstrates a sacral neural crest contribution to the enteric nervous system of chick and mouse embryos. Development 111:857-866.

Southwell BR. 2006. Staging of intestinal development in the chick embryo. Anat Rec A Discov Mol Cell Evol Biol 288:909-920.

Sosa-Pineda B, Wigle JT, Oliver G. 2000. Hepatocyte migration during liver development requires Prox1. Nat Genet 25:254-255.

Stergiopoulos A, Elkouris M, Politis PK. 2015. Prospero-related homeobox 1 (Prox1) at the crossroads of diverse pathways during adult neural fate specification. Front Cell Neurosci $8: 454$.

Suzuki M, Ohmori Y, Watanabe T. 1996. Projections of neurons in the intestinal nerve of Remak to the chicken intestine. J Auton Nerv Syst 61:79-86.

Tomarev SI, Sundin O, Banerjee-Basu S, Duncan MK, Yang JM, Piatigorsky J. 1996. Chicken homeobox gene Prox 1 related to Drosophila prospero is expressed in the developing lens and retina. Dev Dyn 206:354-367.

Uesaka T, Young HM, Pachnis V, Enomoto H. 2016. Development of the intrinsic and extrinsic innervation of the gut. Dev Biol 417:158-167. 
Vandesompele J, De Preter K, Pattyn F, Poppe B, Van Roy N, De Paepe A, et al. Accurate normalization of real-time quantitative RT-PCR data by geometric averaging of multiple internal control genes. Genome biology 2002;3(7):RESEARCH0034

Wang J, Kilic G, Aydin M, Burke Z, Oliver G, Sosa-Pineda B. 2005. Prox1 activity controls pancreas morphogenesis and participates in the production of "secondary transition" pancreatic endocrine cells. Dev Biol 286:182-194.

Wang X, Chan AK, Sham MH, Burns AJ, Chan WY. 2011a. Analysis of the sacral neural crest cell contribution to the hindgut enteric nervous system in the mouse embryo. Gastroenterology 141:992-1002.

Wang H, Bonnet A, Delfini MC, Kawakami K, Takahashi Y, Duprez D. 2011b. Stable, conditional, and muscle-fiber-specific expression of electroporated transgenes in chick limb muscle cells. Dev Dyn 240:1223-1232.

Westmoreland JJ1, Kilic G, Sartain C, Sirma S, Blain J, Rehg J, Harvey N, Sosa-Pineda B. 2012. Pancreas-specific deletion of Prox1 affects development and disrupts homeostasis of the exocrine pancreas. Gastroenterology 142:999-1009.

Wigle JT, Chowdhury K, Gruss P, Oliver G. 1999. Prox1 function is crucial for mouse lensfibre elongation. Nat Genet 21:318-322.

Wigle JT, Oliver G. 1999. Prox1 function is required for the development of the murine lymphatic system. Cell 98:769-778.

Yntema CL, Hammond WS. 1954. The origin of intrinsic ganglia of trunk viscera from vagal neural crest in the chick embryo. J Comp Neurol 101:515-541. 


\section{SUPPLEMENTAL FIGURE LEGENDS}

SUPPLEMENTAL FIGURE 1 Characterization of the rabbit anti-PROX1 antibody by western blot and immunofluorescence analysis. Western blot analysis using increasing concentrations of E15 pancreas-duodenum protein extracts demonstrated a unique band of about $83 \mathrm{kDa}$ that corresponds to the predicted size of chick PROX1 (a). Immunofluorescence analysis of PROX1 expression in E15 chick pancreas cryostat sections (b). PROX1-positive cells are only observed in the pancreatic epithelium, with a nuclear localization. Scale bar: $100 \mu \mathrm{m}$.

SUPPLEMENTAL FIGURE 2 Expression of $P R O X 1$ mRNA in the chick developing colorectum. Whole-mount in situ hybridization analysis of PROX1 (a) and SOX10 (b) in E8 chick colons. PROXI expression is observed in the NoR and the pelvic plexuses (PP, arrows) at E8. PROX1 expression is also present in fibers that connect the PP to the NoR (arrowheads). SOX10 expression is observed in the NoR, in migrating vNCCs and in the pelvic plexus (PP) at E8 (arrows). Scale Bars: $200 \mu \mathrm{m}$.

SUPPLEMENTAL FIGURE 3 Spatial and temporal PROX1 expression in the chick developing colon. Immunofluorescence analysis of PROX1 and TUJ1 expression in E6.5 to E9.5 chick colon transverse cryosections (focus on the NoR). TUJ1 is observed in sNCCs located in the NoR from E6.5 to E9.5. At E7.5, few TUJ1-positive sNCCs entered the outer part of the colon mesenchyme. At E6.5, PROX1 is observed in the majority of cells present in the NoR. PROX1 expression in these cells strongly decreased from E7.5 to E8.5 to finally be present only in some isolated cells at E9.5. PROX1 expression was also observed in lymphatic endothelial cells (white arrows) close to the NoR. Scale bars: $100 \mu \mathrm{m}$. 
SUPPLEMENTAL TABLE 1 Gallus gallus primers used for RT-qPCR.

SUPPLEMENTAL TABLE 2 Microarray data used for producing the Heatmap (Figure 1a) that summarizes the expression of PROX1, SM22, CNN1, SOX10 and RET in chick colon (from E5, E6, and E9) and gizzard (E6 and E9) samples, with their corresponding $p$ values. 
(a)

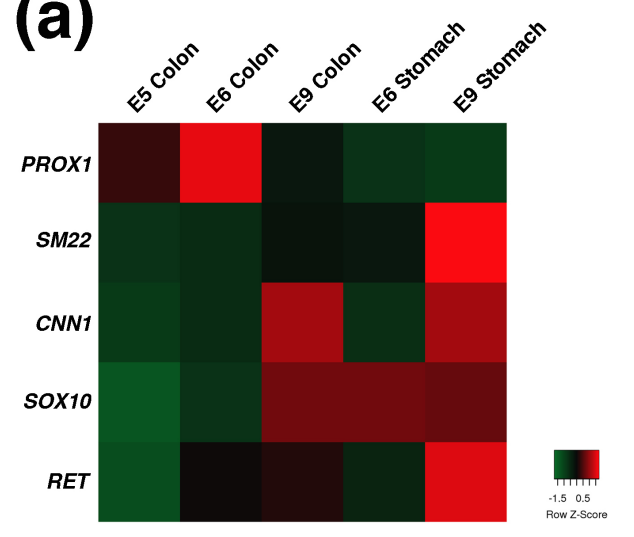

(c)

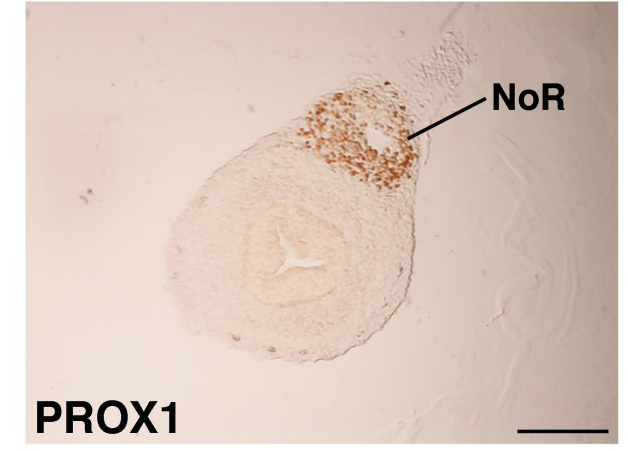

(d)

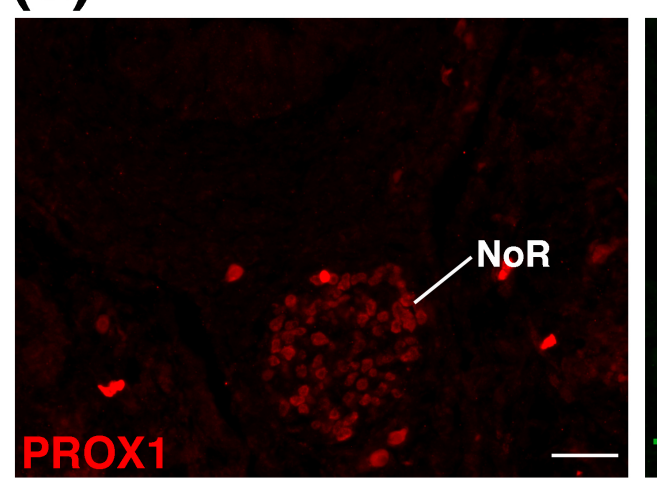

(e)

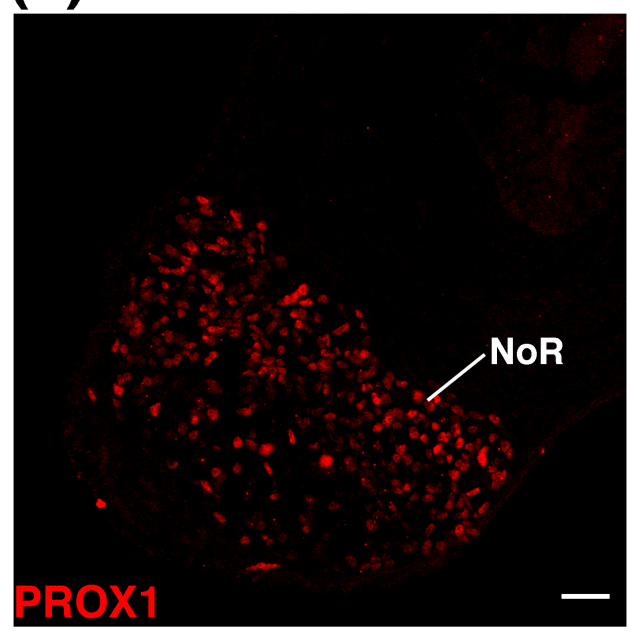

(b)
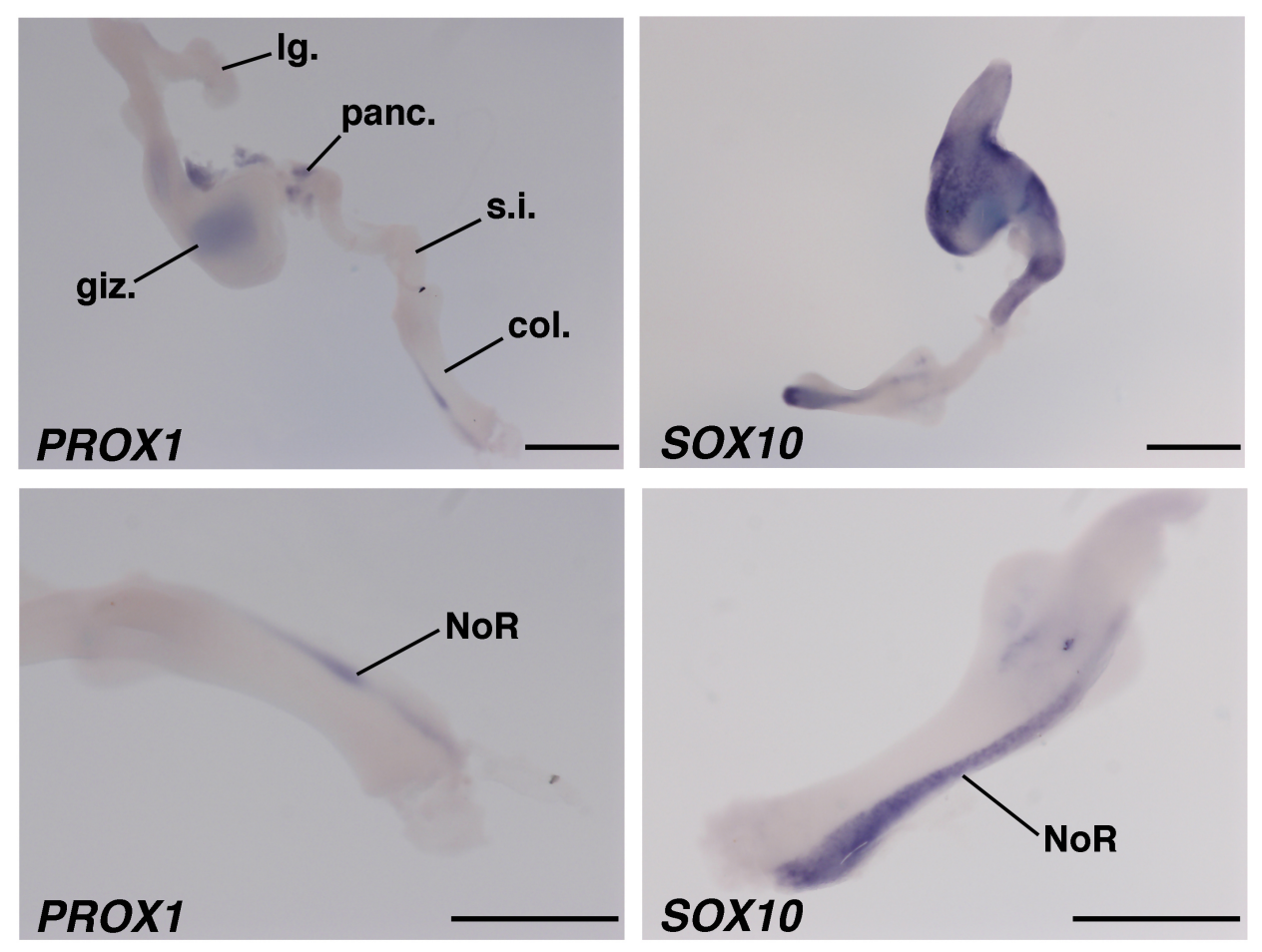


PROX1/TUJ1
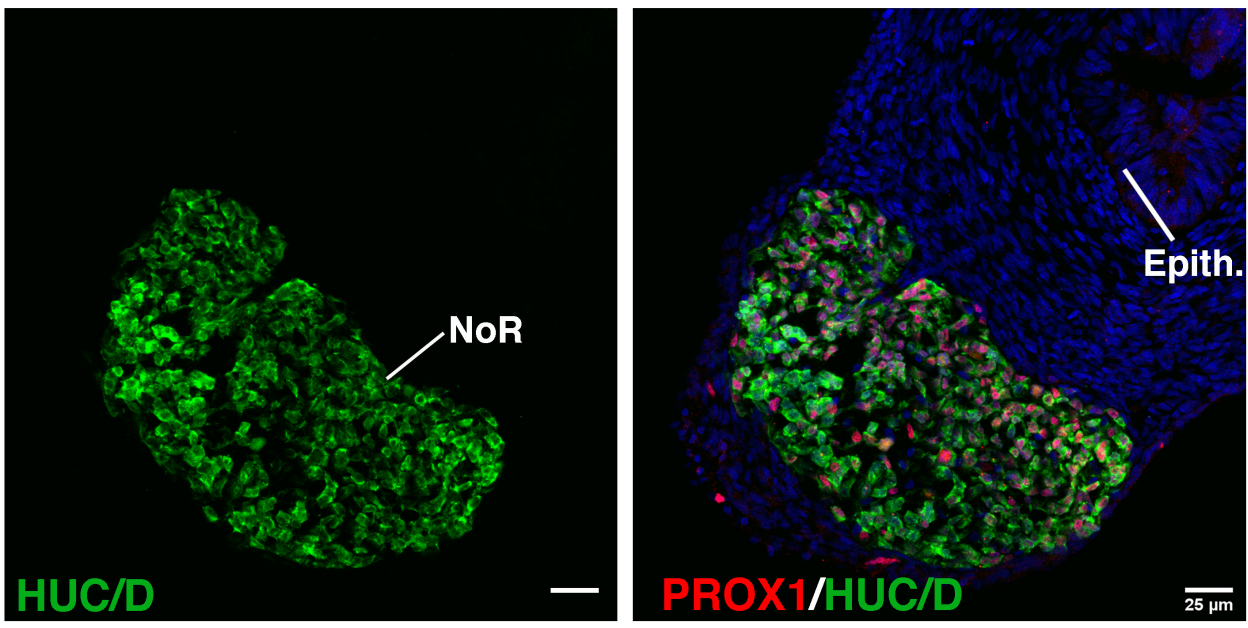
(a)

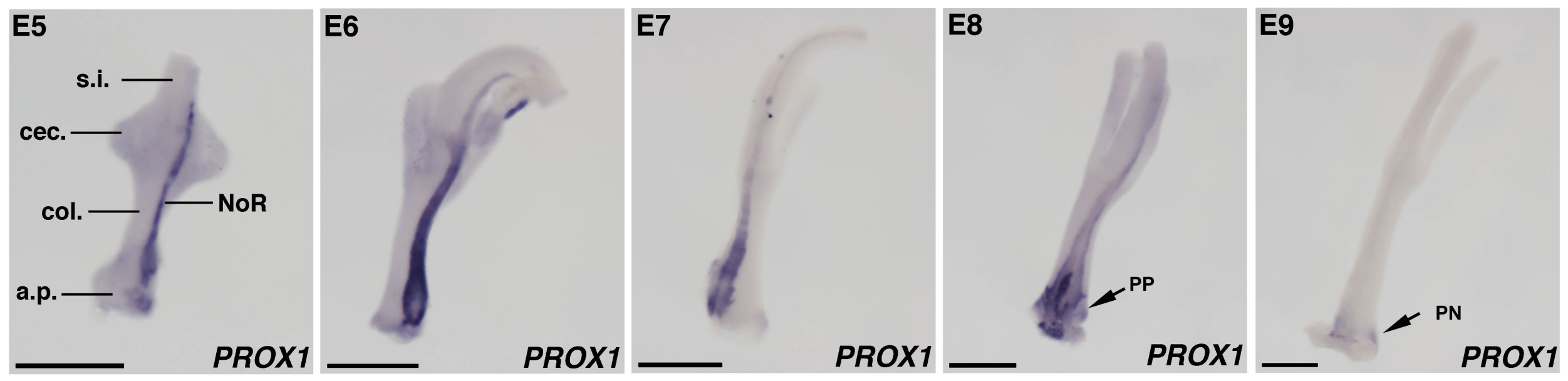

(b)
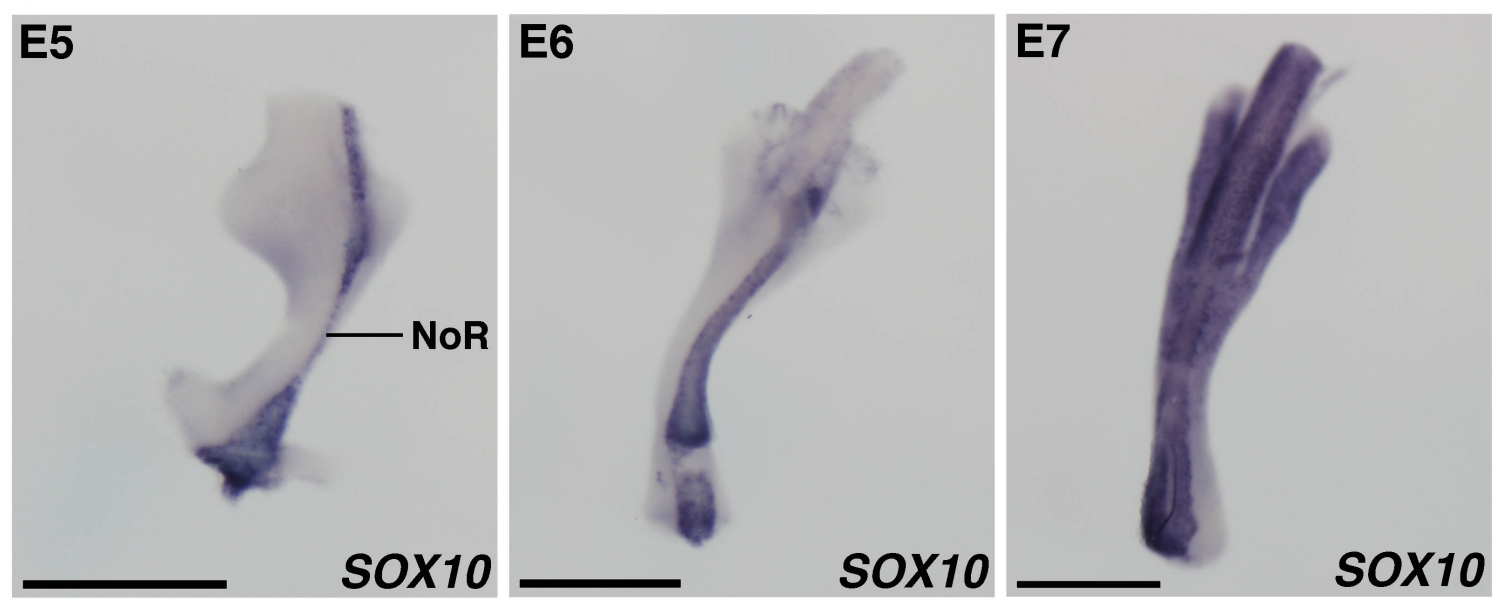

E8

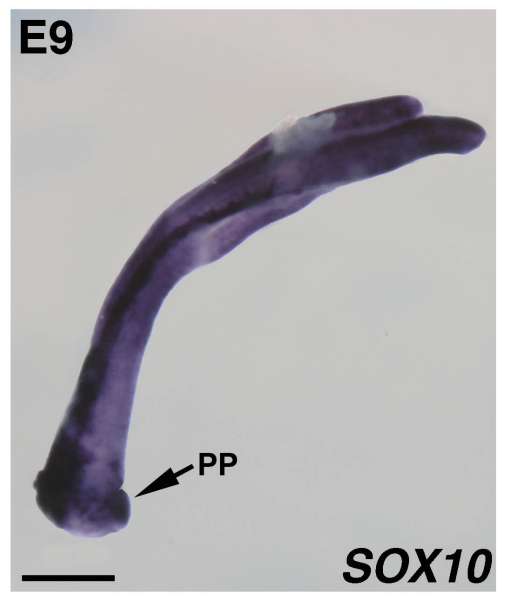

(c)

(d)

sox10

(e)

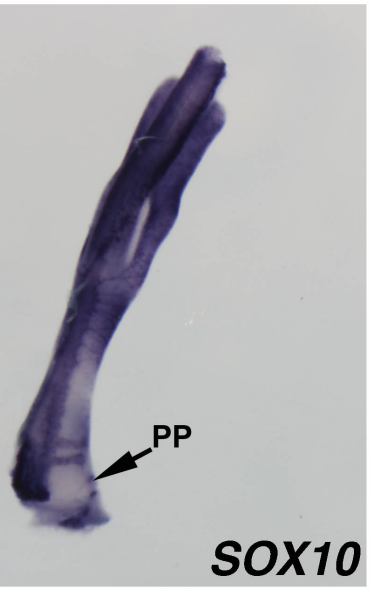

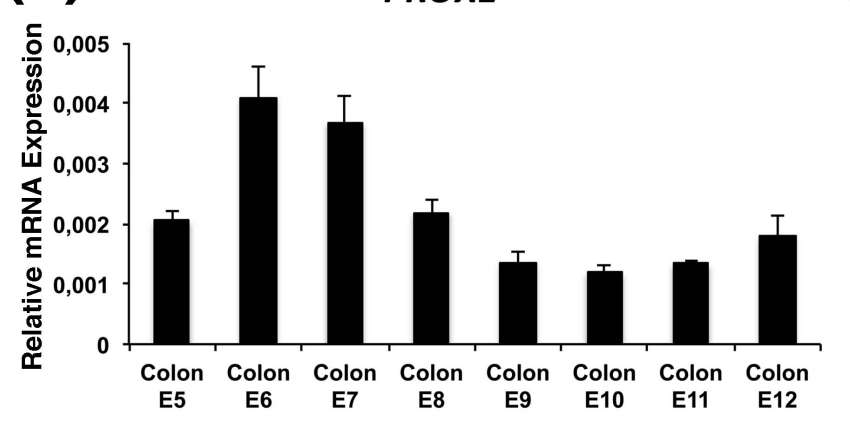
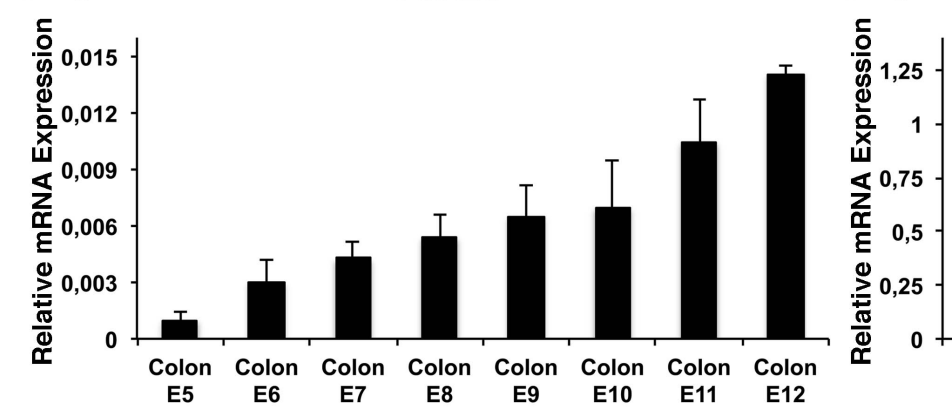

SM22 


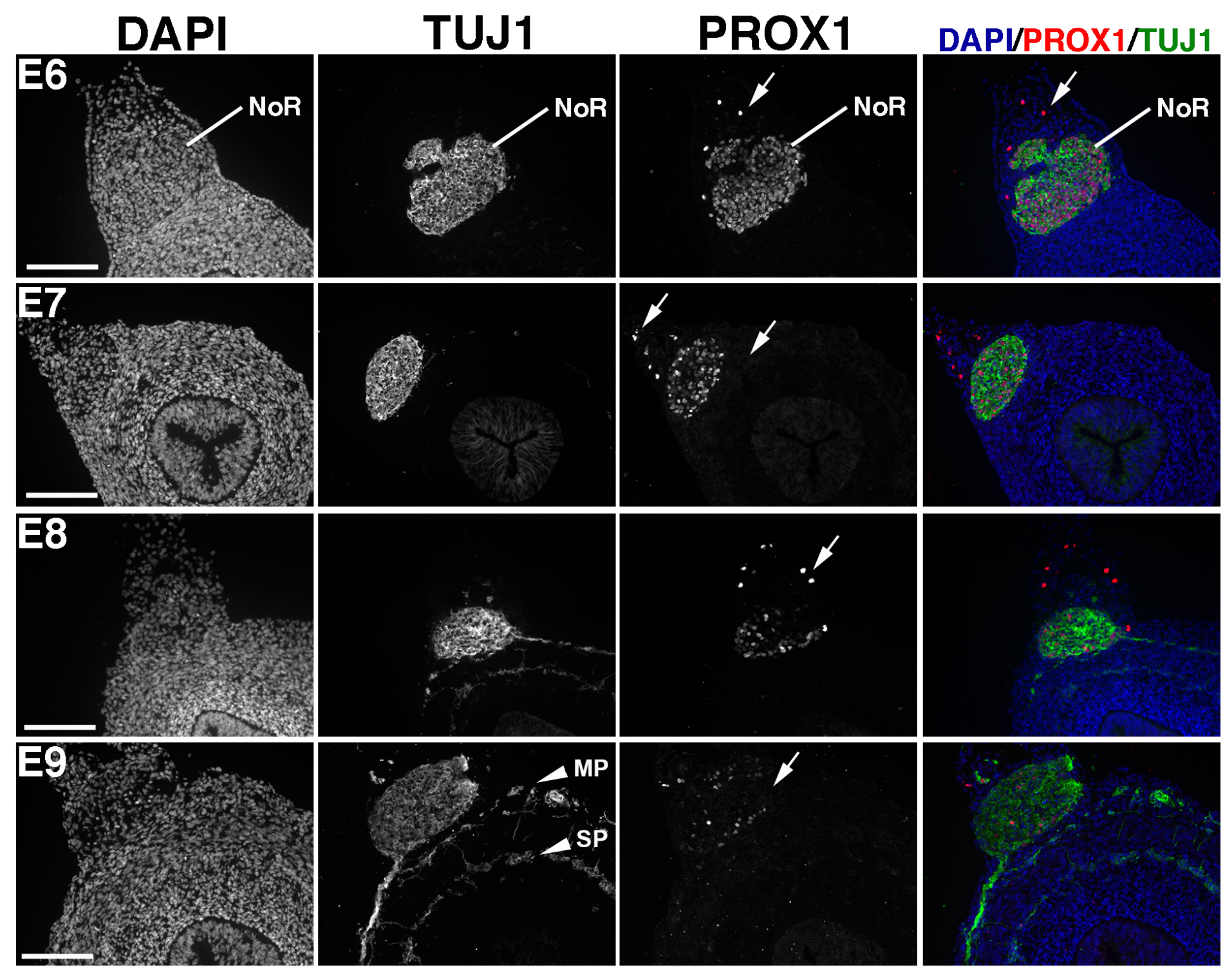




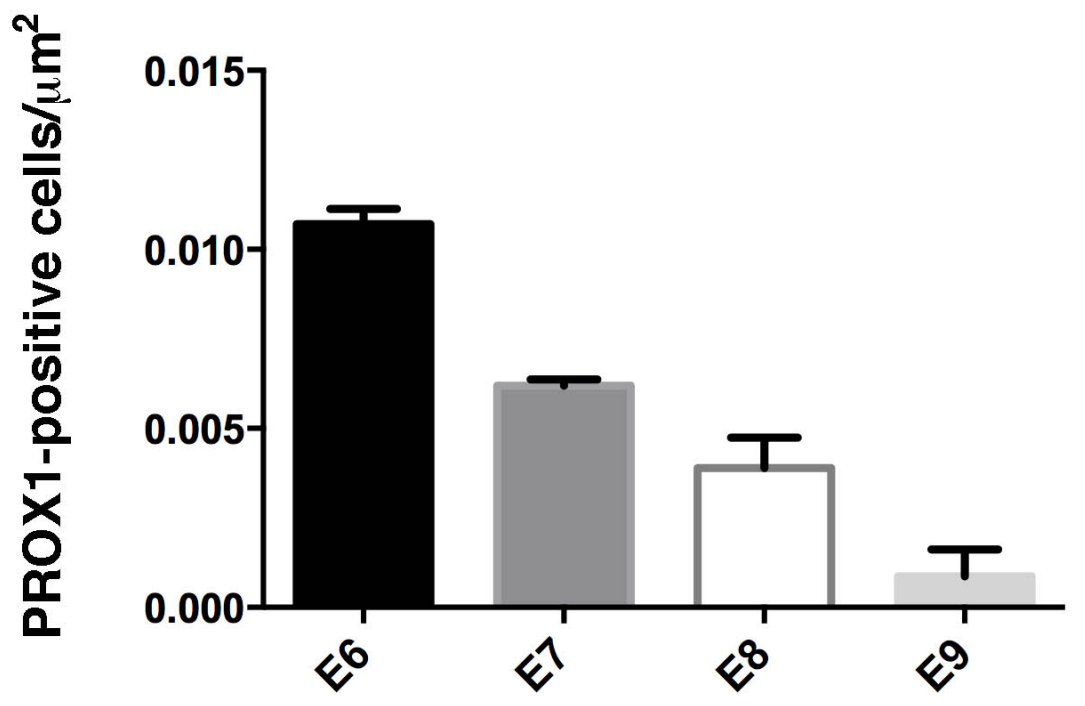


(a)

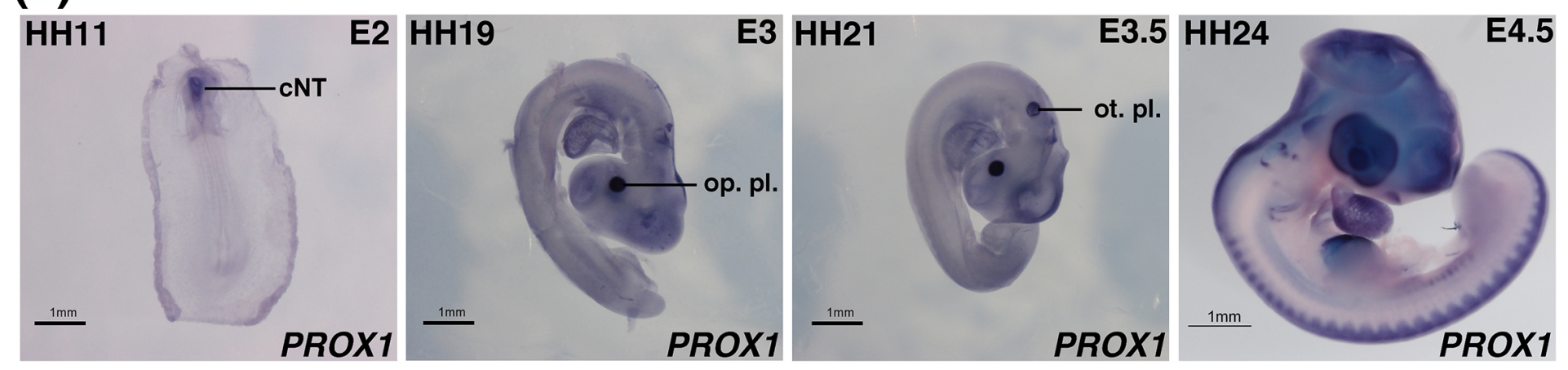

(b)

\section{HH18}
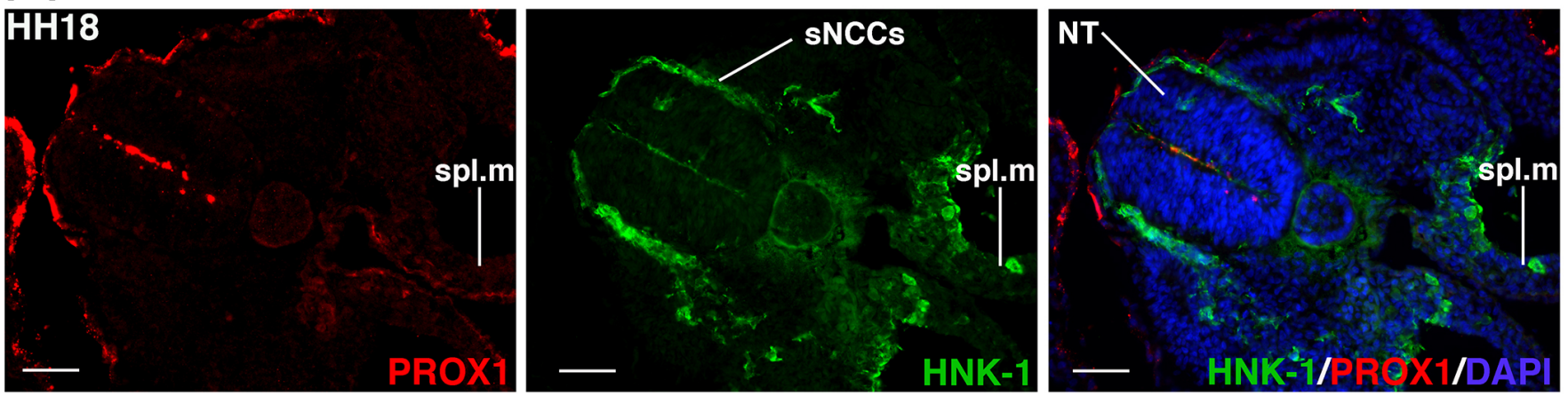

\section{(c)}

\section{HH19}
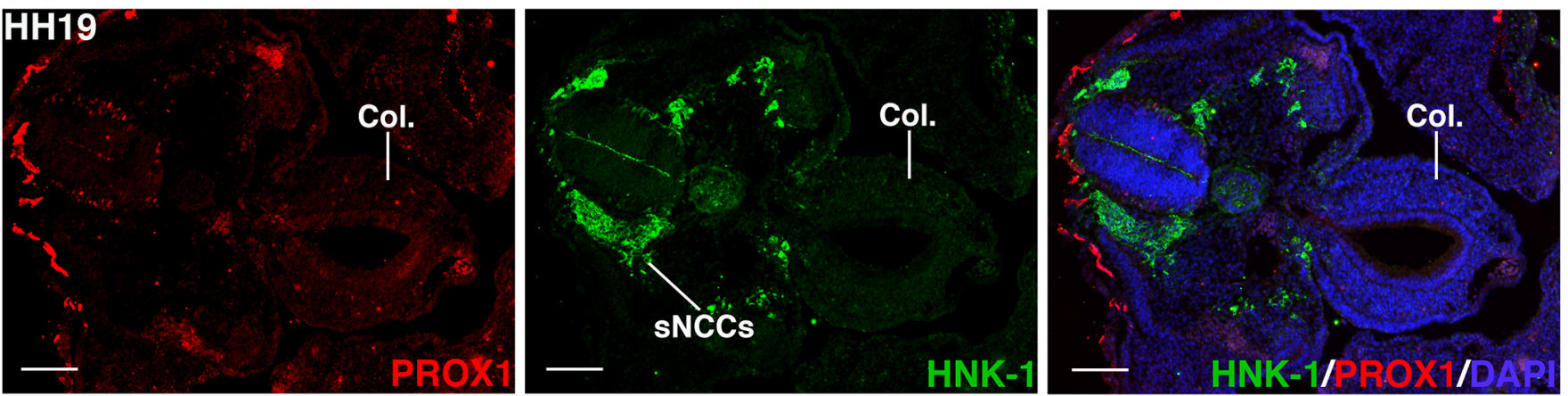

\section{(d)}

\section{HH23}

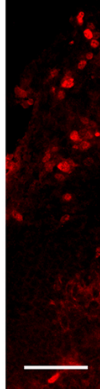

Col.

PRo)

HNK-1

HNK-1/PROX/DAP

\section{(e)}
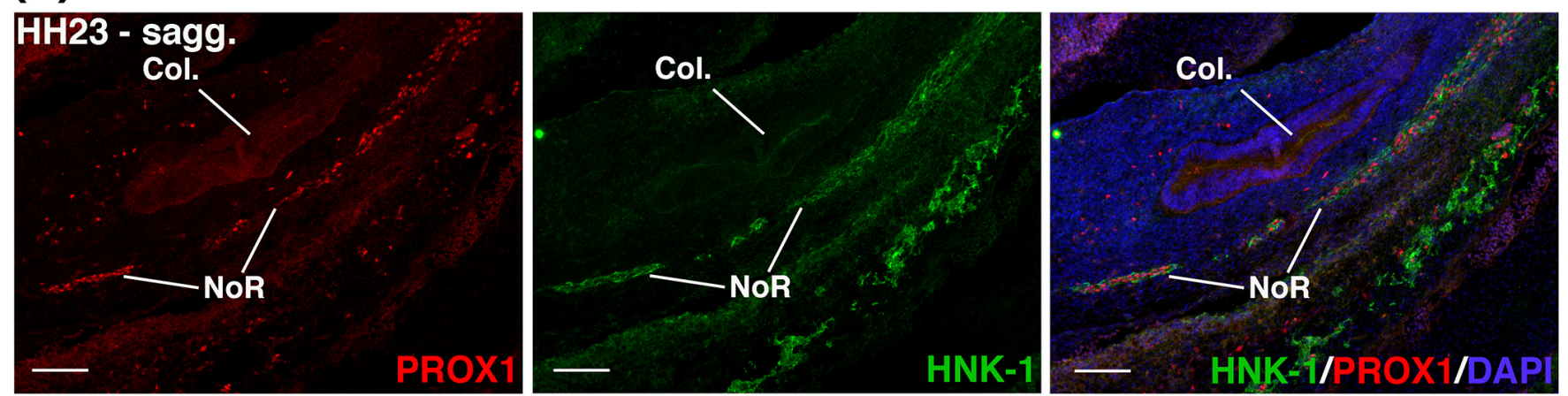
(a)

sacral NCCs

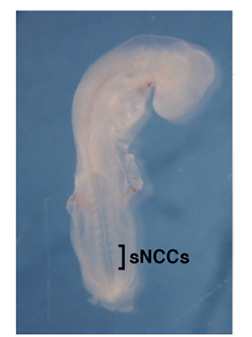

(b)

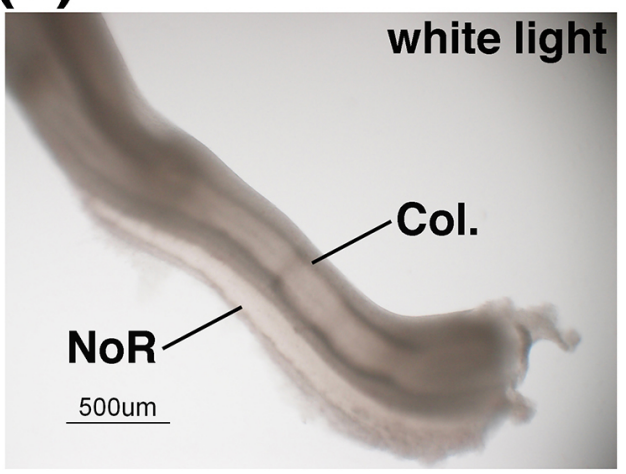

(c)

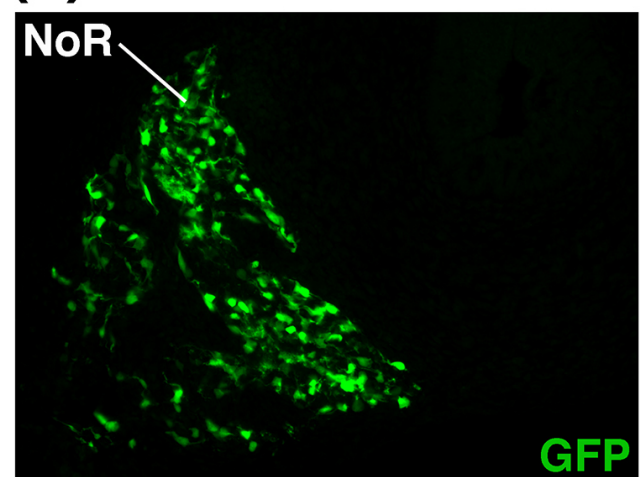

electroporation of GFP-expressing
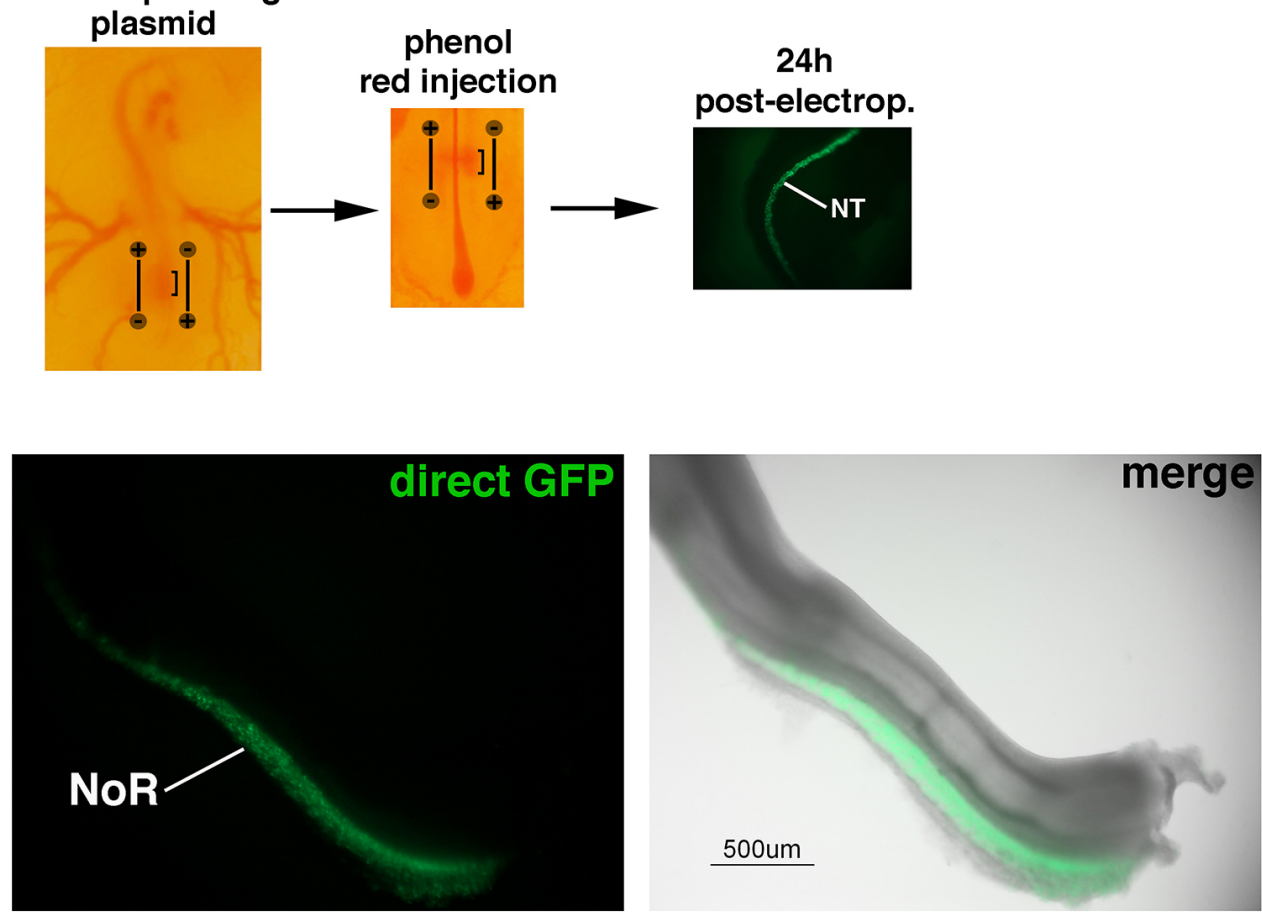
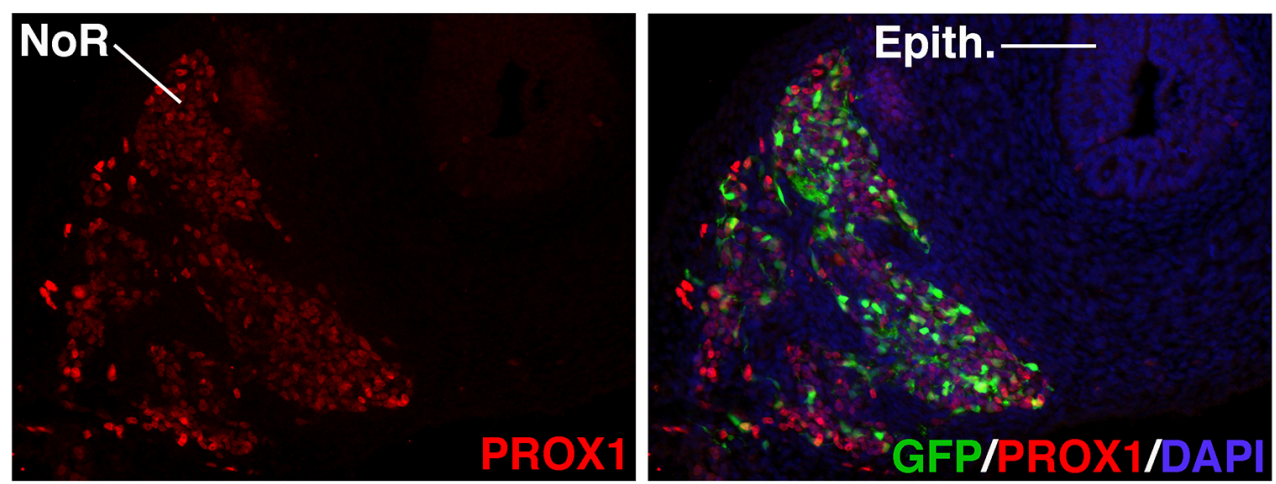

(d)
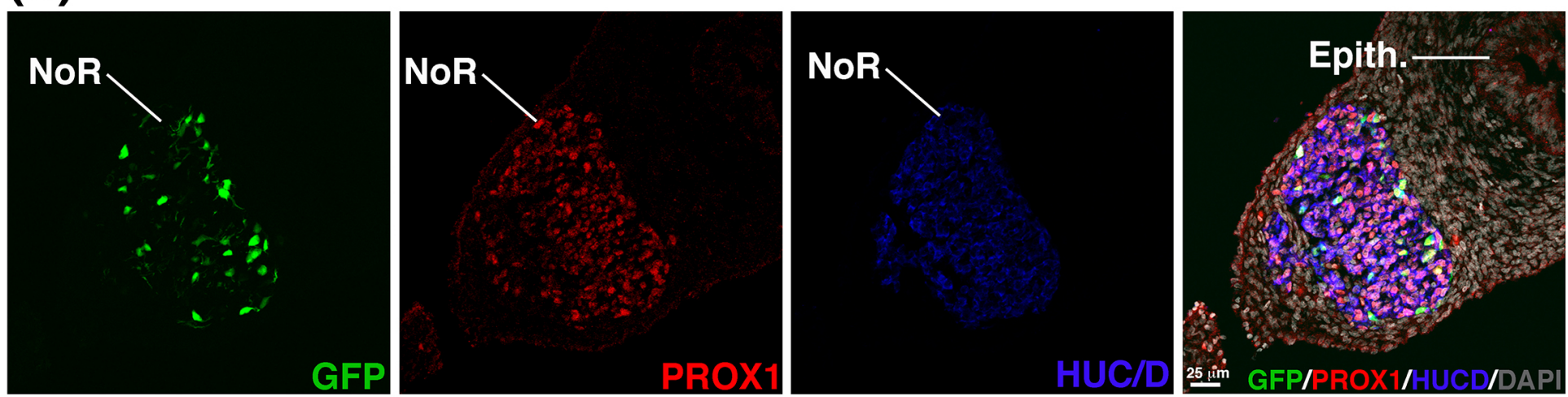
Supplementary Table 1: Gene-specific Gallus Gallus primers used for RT-qPCR.

\begin{tabular}{|c|l|l|c|}
\hline Targets & \multicolumn{1}{|c|}{ Forward primer (5'-3') } & \multicolumn{1}{|c|}{ Reverse primer (5'-3') } & Amplicon (bp) \\
\hline PROX1 & AAT CTC GCC CTA CTC GGG AA & GGT AAT GCA TCT GTT GAA CTT TAC A & 151 \\
\hline SOX10 & GCA TCG GAC AAC TCT TCG & CCA GTC ATA GCC GCT A & 150 \\
\hline SM22 & TGA GCA GGG ATG TCC AGT & AGC CAA TGA TGT TCT TGC C & 501 \\
\hline GAPDH & CGT CCT CTC TGG CAA AG & TCA CGC TCC TGG AAG ATA G & 177 \\
\hline
\end{tabular}




\section{Supplementary Table 2: Microarray data used for Heatmap in Figure 1a.}

Microarray values

$\begin{array}{lrrrrr} & \text { E5 Colon } & \text { E6 Colon } & \text { E9 Colon } & \text { E6 Stomach } & \text { E9 Stomach } \\ \text { PROX1 } & 113,5168 & 201,6 & 72,06155 & 32,7 & 22,4 \\ \text { SM22 } & 337,0399 & 479,7 & 844,1374 & 768,1 & 2757,9 \\ \text { CNN1 } & 45,48849 & 148,1 & 769,3994 & 127,6 & 764,3 \\ \text { SOX10 } & 53,06907 & 104,4 & 220,6422 & 224,1 & 216,2 \\ \text { RET } & 153,1164 & 301,4 & 319,4413 & 240,6 & 464,5\end{array}$

Microarray $\boldsymbol{P}$ values

$\begin{array}{llrrrr} & \text { E5 Colon } & \text { E6 Colon } & \text { E9 Colon } & \text { E6 Stomach } & \text { E9 Stomach } \\ \text { PROX1 } & 0,00024414 & 0,000244 & 0,00024414 & 0,00415 & 0,056152 \\ \text { SM22 } & 0,00073242 & 0,000732 & 0,00024414 & 0,000732 & 0,000244 \\ \text { CNN1 } & 0,00024414 & 0,000244 & 0,00024414 & 0,000244 & 0,000244 \\ \text { SOX10 } & 0,00024414 & 0,023926 & 0,00024414 & 0,001953 & 0,00293 \\ \text { RET } & 0,00024414 & 0,000244 & 0,00024414 & 0,000244 & 0,000244\end{array}$

Relative values reported to the maximum of expression

$\begin{array}{lcrrrrr} & \text { E5 Colon } & \text { E6 Colon } & \text { E9 Colon } & \text { E6 Stomach } & \text { E9 Stomach } \\ \text { PROX1 } & 0,56307937 & 1 & 0,35744816 & 0,16220238 & 0,11111111 \\ \text { SM22 } & 0,12220889 & 0,17393669 & 0,30607977 & 0,27850901 & 1 \\ \text { CNN1 } & 0,05912208 & 0,1924878 & 1 & 0,16584364 & 0,99337223 \\ \text { SOX10 } & 0,23680977 & 0,46586345 & 0,98457028 & 1 & 0,96474788 \\ \text { RET } & 0,32963703 & 0,64886975 & 0,68771001 & 0,51797632 & 1\end{array}$


(a)

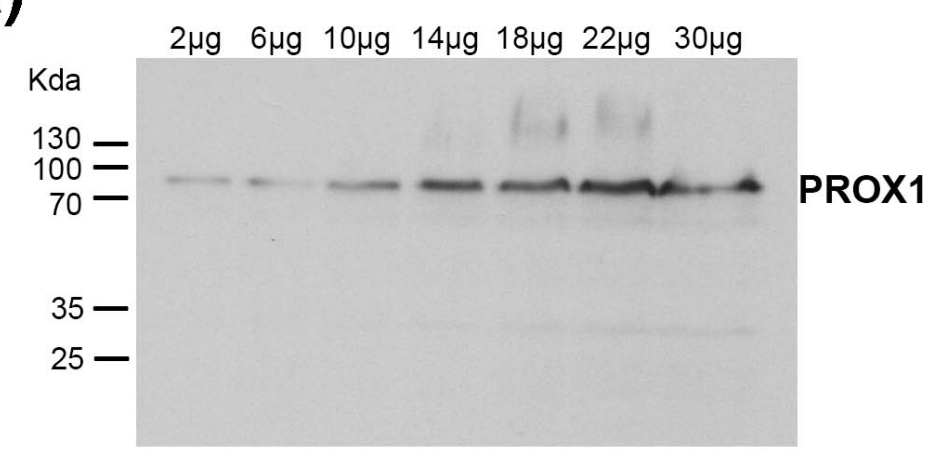

(b)

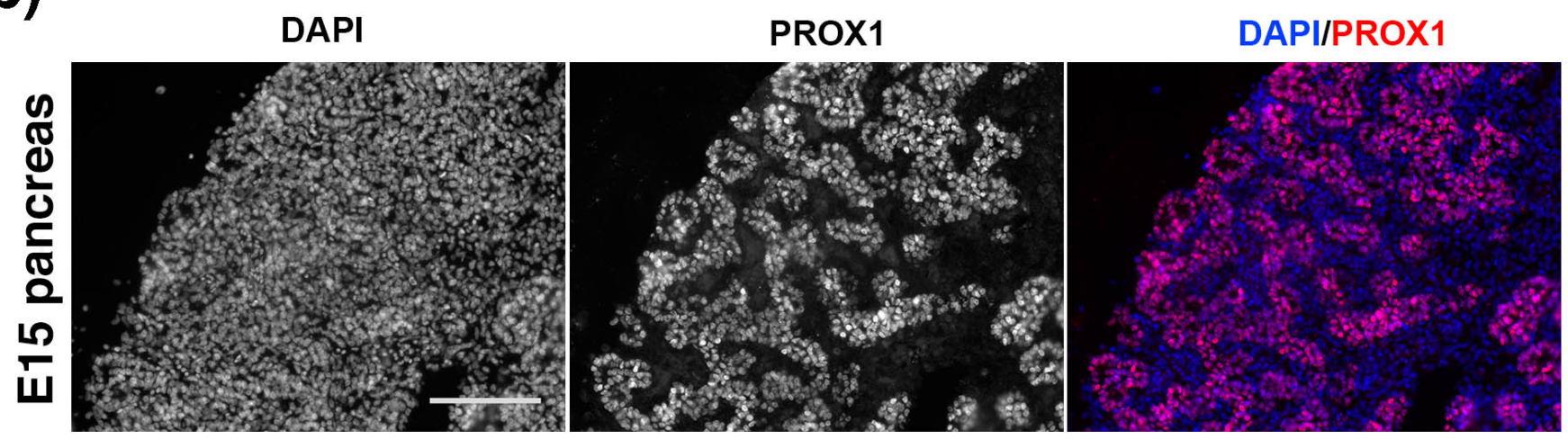

Scale bar $=100 \mu \mathrm{m}$ 


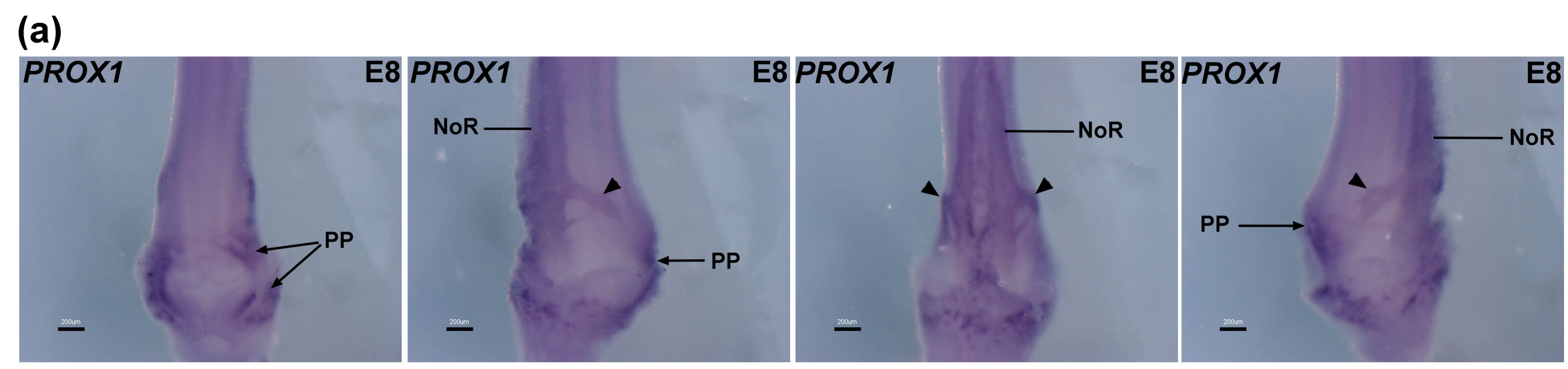

(b)

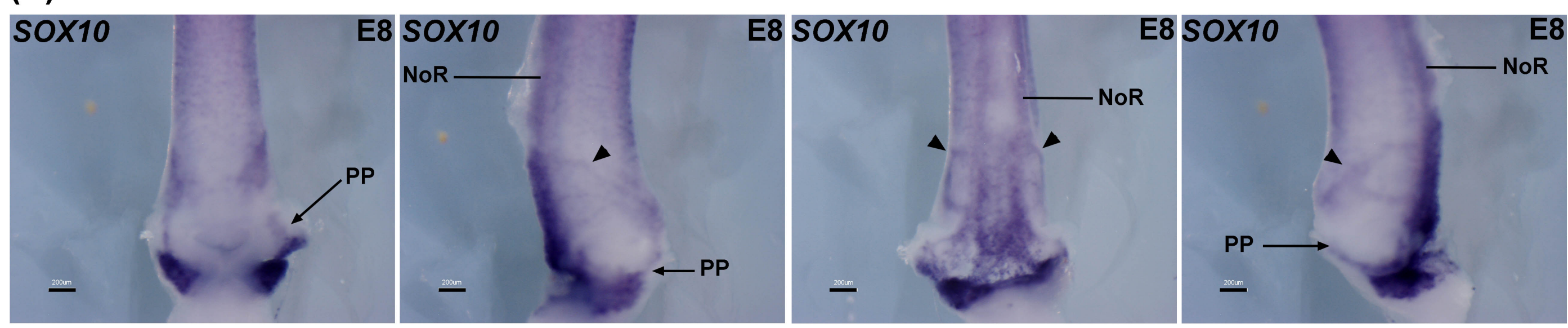




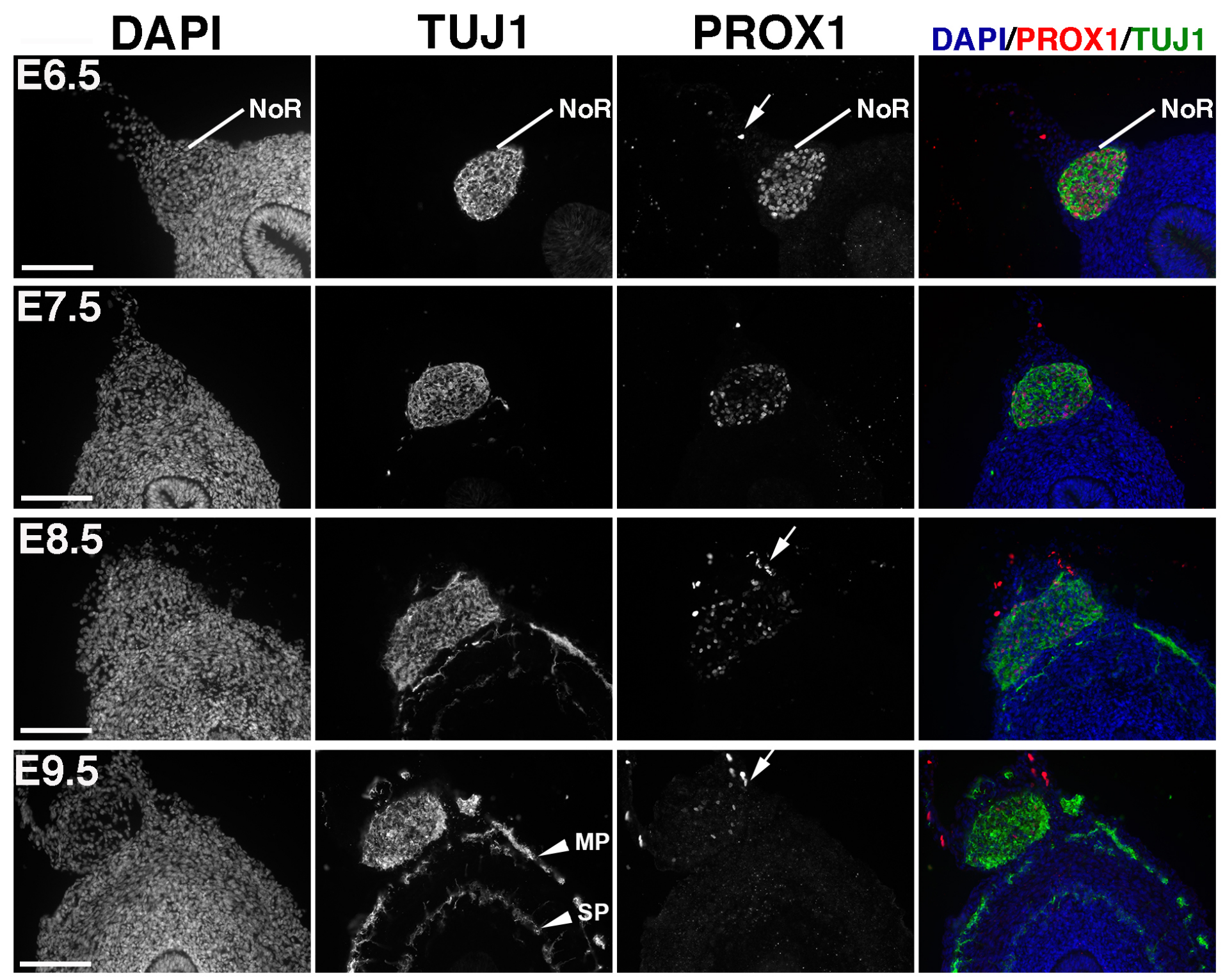




\section{Graphical Abstract}

The Enteric Nervous System ensures the intrinsic innervation of the gastrointestinal tract and originates from vagal and sacral Neural Crest Cells. In birds, sacral Neural Crest Cells (sNCCs) first give rise to an extramural ganglionated structure: the Nerve of Remak (NoR) and the Pelvic Plexus. Later, sNCCs colonize the colon mesenchyme and contribute to the intrinsic innervation of the caudal part of the gut. Here, we show that PROX1 is expressed in SNCCs localized in the NoR and in the pelvic plexus. Using in vivo cell tracing, we demonstrated that sNCCs are the source of the PROX1-positive cells within the NoR. This work identifies PROX1 as a novel and thus far unique marker that defines sNCCs. 

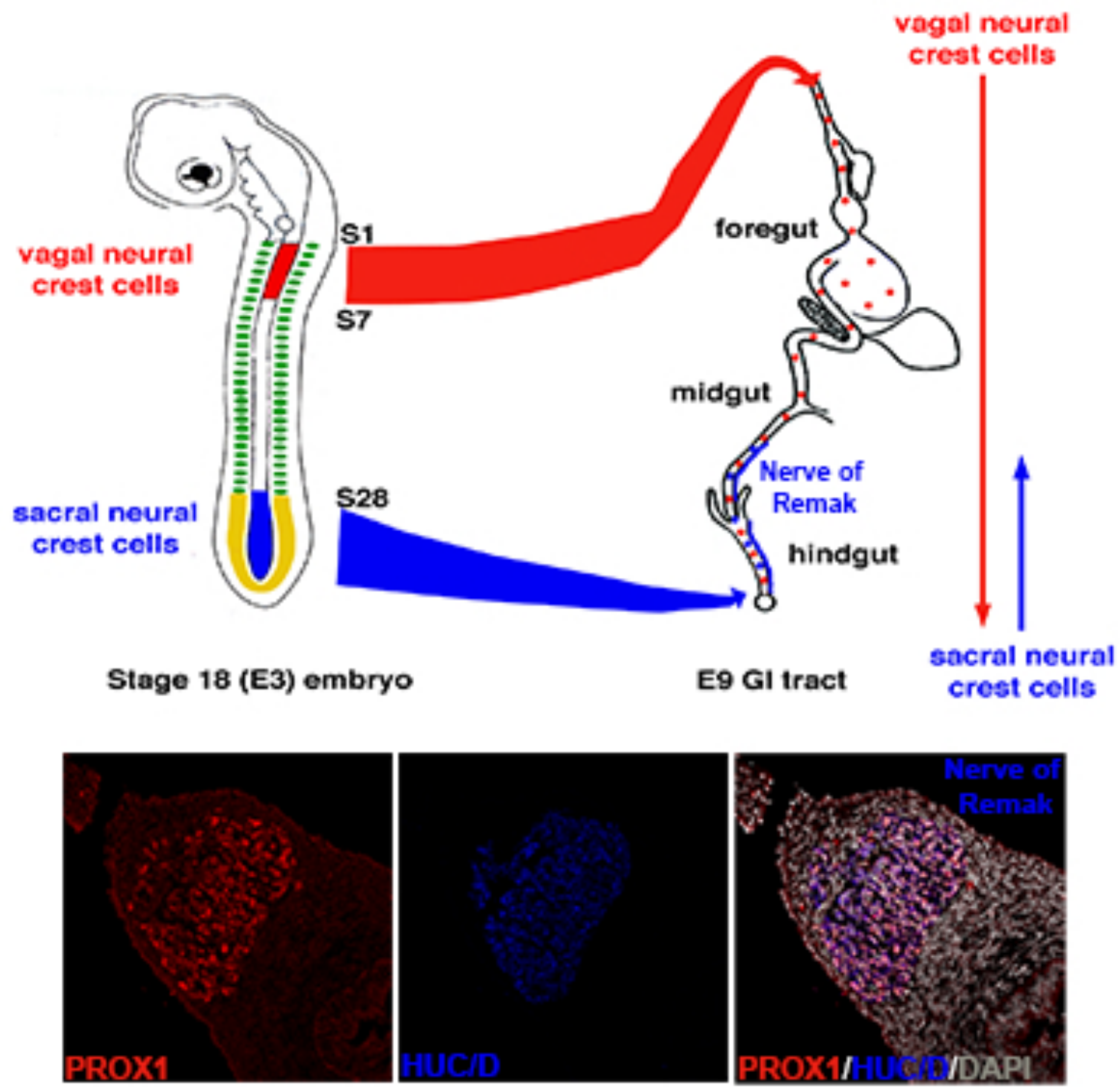